\title{
THE DEVELOPMENT OF SULFONYLUREA HERBICIDE RESISTANT BIRDSFOOT TREFOIL (LOTUS CORNICULATUS) PLANTS FROM IN VITRO SELECTION
}

\author{
by \\ Shoshana Pofelis
}

\begin{abstract}
A thesis submitted to the Faculty of Graduate studies and Research in partial fulfilment of the requirements for the degree of Master of Science
\end{abstract}

Shoshana Pofelis (c)

Department of Biology

MCGill University

Montreal 


\section{Abstract}

Birdsfoot Trefoil (Lotus corniculatus L. cv. Leo), is a perennial forage legume that has difficulty in establishing stands due to slow seedling growth, weed competition and herbicide sensitivity. The development of herbicide resistant cultivars would be of economic importance. Resistant lines were isolated after sequential selection at the callus, shoot and whole plant levels to the sulfonylurea (SU) herbicides Harmony (DPX-M6316, code name for methyl 3-[[[(4-methoxy-6-methyl$1,3,5, \operatorname{triaz} i n e-2-y 1$ ) aminol carbonyl ] aminolsulfony $1-2$ thiophenecarboxylate), or Classjc (DPX-F6025, code name for 2 ( ( [ 4-chloro-6-methoxypyrimidine-yl)amino carbony 1 ) aminosulfonyl)benzoic acid ethyl ester. In field and growth chamber tests the Harmony regenerant lines displayed an increased tolerance as compared to control plants from tissue culture, and from seed. Results of the evaluation of callus cultures of regenerated mutant lines signify stability of the resistance. Outcrossed seeds collected from field trials, and tested in vitro for herbicide resistance, indicate that the trait is heritable and that resistance may be due to reduced sensitivity of acetolactate synthase to su inhibition. It is concluded that herbicide resistant birdsfoot trefoil cultivars can be isolated using in vitro selection. 


\section{RESUME}

Le Lotier corniculé ( $\underline{L}$. corniculatus $L$. $c v$. Leo) est une légumineuse fourragère vivace qui produit des cultures sur pied non sans difficultés dû à une croissance lente des semis et la compétition venant des mauvaises herbes. Ainsi, le développement de cultivars résistants à certains herbicides est d'une grande importance économique. Des lignées résistantes aux herbicides à base de sulfonylurée, Harmony (DPX-M6316) ou Classic (DPXF6025), ont été sélectic rées au niveau de cals, pousses et de plantes entières. Dans des tests sur le terrain et en chambres de croissance, les lignées régénérées ont montré une plus grande tolérance que les plantes témoins issus de culture de tissu et de graines. L'évaluation des cultures de cals provenant de lignées de variants régénérés ont montré une stabilité dans la résistance. Des graines provenant de la reproduction croisée d'essais sur le terrain, germées in vitro net testées pour leur résistance aux herbicides ont révélé que le trait est transmissible héréditairement et que la résistance pouvait être due à une diminution de la sensibilité de l'acétulactate synthase à l'inhibition de la sulfonylurée. On en déduit que des cultivars de Lotier corniculé résistants aux herbicides peuvent être isolés en utilisant des techniques de sélection in vitro. 


\section{Acknowledgments}

Above all I would like to thank Dr. W. F. Grant, my supervisor, for his generosity, support and confidence in my work throughout this project. I would like to express my gratitude to him for encouraging me to pursue my studies and to continue my work as a research assistant at the same time. I also want to thank my committee members Dr. D. Donnelly and Dr. R. Dhindsa. My appreciation is extended to Richard Stahl for help with the enzyme assay and field work and Pierre st. Marseille for the French translation of the abstract. Dr. M.A. Fanous and Dean Spaner for statistical advise and Ms. H. Rimmer for the photography lessons are gratefully acknowledged. I especially appreciate the friendship and discussions with my fellow laboratory colleagues Suyanee Vessebatr, Lazara Compos, Susan Delafield and Hoan Le. 


\section{Table of Contents}

Page

Abstract . . . . . . . . . . . . . . . . . . ii

Sommaire . . . . . . . . . . . . . . . . . . . . .

Acknowledgments. . . . . . . . . . . . . . . . iv

Table of Contents. . . . . . . . . . . . . . . . . v

List of Tables. . . . . . . . . . . . . . . . . viii

List of figures. . . . . . . . . . . . . . . . . . ix

List of Abbreviations. . . . . . . . . . . . . . . . xi

List of Apfendices . . . . . . . . . . , . . . . . . xii

1. Introduction. . . . . . . . . . . . . . . . 1

2. Literature Review . . . . . . . . . . . . . 3

2.1. In vitro selection for herbicide resistance. . 3

2.2. Somaclonal variation . . . . . . . . . . . 4

2.3. Cytological studies of cells from tissue cilture 5

2.4. Herbicide tolerance/resistance - Epigenetic/genetic variation . . . . . . . . . . . . . . . 8

2.5. Sulfonylurea herbicides. . . . . . . . . 10

2.6. Experimental research - sulfonylurea herbicides 13

2.7. Experimental research - birdsfoot trefoil. . . 16

3. Materials and Methods . . . . . . . . . . . . 20

3.1. Culture Procedure. . . . . . . . . . . . 20

3.1.A. Media preparation . . . . . . . . 20

3.1.B. Callus initiation . . . . . . . . . 20

3.2. Selection for Resistance . . . . . . . . . 21

3.2.A. Selection I - using callus culture. . . 21 
3.2.B. Selection II - using regenerated shoots

3.2.C. Selection III - using plants. . . . . . 24

3.3. Evaluation of Resistance . . . . . . . . . 28

3.3.A. Callus test of regenerant lines.... . 28

3.3.B. Growth chamber analysis. . . . . . . 28

3.3.C.i. Field analysis 1989 . . . . . . . 29

3.3.C.ii. Field analysis 1990... . . . . . . 31

3.3.D. Cytogenetic studies . . . . . . . . 32

3.3.E. ALS enzyme assay. . . . . . . . . . . . 32

3.3.F. In vitro seed germination trials. . . . 35

4. Results and Discussion. . . . . . . . . . . . . . 36

4.1. Selection for Resistance . . . . . . . . . 36

4.1.A. Selection I. . . . . . . . . . . . 36

4.1.B. Selection II............... 40

4.1.C. Selection III... . . . . . . . . . 45

4.2. Evaluation of Resistance at the Cell Level-Callus 49

4.3. Evaluation of Resistance at the whole Plant Level 54

4.3.A. Growth Chamber and Field Analysis. . . 54

4.3.A.i. Phytotoxicity. . . . . . . . 54

4.3.A.ii. Yield.......... . . 63

4.3.A.iii. Flowering and Fertility. . . . 64

4.3.B. Plant line H4-10. . . . . . . . . 65

4.4. Ir. Vitro Seed Germination. . . . . . . . . . . 67

4.5. Cytogenetics. . . . . . . . . . . . . . 71

4.6. Acetolactate Synthase Enzyme assay. . . . . . . 72

5. Summary and Conclusions . . . . . . . . . . . 80 
1

6. References. . . . . . . . . . . . . . . . . . 85

7. Appendices. . . . . . . . . . . . . . . . . 92 


\section{List of Tables}

Table

Page

3.1. Herbicide concentrations used for selection I:

Callus level.

3.2. Herbicide concentrations used for selection III:

Plant level. . . . . . . . . . . . . . . . 27

3.3. Herbicide concentrations used in growth chamber and field tests. . . . . . . . . . . . . . . . . 27

4.1. Means of callus fresh weight ( $g$ ) after two weeks on B5M medium (control) or selection media; supplemented with Harmony or Classic . . . . . . . . . . . . . . 39

4.2. Survival after selectic.l II - Shoots. . . . . . . . 47

4.3. Survival after selection III - whole plant. . . . . . 48

4.4. Effect of herbicide on callus growth of regenerants . 52

4.5. Indoor study: Effect on height prior to and 6 weeks after herbicide application to cuttings of selected regenerant lines. . . . . . . . . . . . . . . . . . 55

4.6. LSD for multiple comparisons of mean injury rating of simple effects of cell lines at each herbicide level. 61

4.7. Variety trial (1990). . . . . . . . . . . . . . 66

4.8. Effect of herbucide on seeds of resistant lines germinated in vitro................. . 70 


\section{List of Figures}

Figure

Page

1.a. Leo callus, passage 5, on Harmony, Classic $\left(10^{-6} \mathrm{M}\right)$ selection and control medium - Selection I. . . . . . 38

1.b. Early shoot development after one month of growth on $\mathrm{B} 5 \mathrm{M}+0.2 \mathrm{mg} / \mathrm{L} \mathrm{NAA}$ - regeneration medium. . . . . . . 38

2.a. Regenerated shoots being placed on control and selection media - Selection II.

2.b. Close-up of shoots on selection media after one week of growth . . . . . . . . . . . . . . . . . . 42

2.c. Same as 2.a., after iwo weeks growth. . . . . . . . . . 42

3.a. Acclimatized plants that had been rooted on media with $0.02 \mathrm{mg} / \mathrm{L}$ NAA (left) and no growth regulators (right). . 44

3.b. Regenerated plants being treated in Spray Chamber . . . 44

4.a. Callus initiation of Leo and two regenerated resistant lines after 20 days growth on MS medium $+2.0 \mathrm{mg}$ 2,4-D......................... 51

4.b. Callus of Leo and five resistant lines after two weeks growth on Harmony $\left(10^{-5} \mathrm{M}\right)$ selection medium. . . . . . 51

4.c. Callus of Leo and resistant line 5-1 after two weeks growth on $0,10^{-5}$ and $10^{-4} \mathrm{M}$ Harmony selection media. . . 51

5. Callus growth of regenerants. . . . . . . . . . . . 53

6.a. Flats of cuttings prior to planting, for field trial, 1989. . . . . . . . . . . . . . . . . . 58

6.b. Line 4-10 (bottom left) and Leo (top right) after three months growth in the field, 1989. . . . . . . . . 58

7. Leo and resistant selection $\mathrm{H} 4-16$ two weeks after herbicide application $(43.76 \mathrm{~g} \mathrm{ai} / \mathrm{ha})$ from field trial. . . . . . . . . . . . . . . 60

8. Growth response to a foliar application of Harmony, from field trial $1989 .$. . . . . . . . . . . . . 62

9.a. Seeds of Leo ard resistant lines $1-1,5-1$, and 5-10 germinating on Harmony $10^{-5} \mathrm{M}$ selection media. . . . . 69 
9.b. Close-up of line 5-1. . . . . . . . . . . . . . . 69

9.c. Comparison of root growth of a resistant line (left) and Leo (right) on selection media . . . . . . . . . 69

10.a. ALS enzyme assay; Leo (left) and line 5-10 (right), herbicide concentration from left to right $0,1,10$,

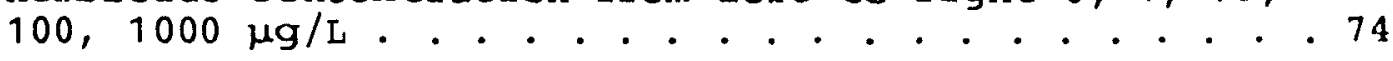

10.b. Chromosomes from line 4-12 showing polyploidy. . . . 74

11. Inhibition of ALS activity by DPX-M6316. . . . . . . . 77

12.a-c. Phenotypic comparison of Leo and polyploid line 4-16, of stem section, flower, and leof. . . . . . . 76 


\section{List of Abbreviations}

$a i=$ active ingredient

ALS = Acetolactate synthase

$\mathrm{BA}=6$-benzyladenine $=(\underline{N}$-phenylmethl $)-1 \underline{H}$-purin-6-amine

$C S=$ Chlorsulfuron

$2,4-D=(2,4-d i c h l o r o p n e n o x y)$ acetic acid

DPX-M6316, code name for methyl 3-[[ [(4-methoxy-6-methyl-

$1,3,5$, triazine-2-y l) amino ]carbonyl ] amino ]sulfony 1-2thiophenecarboxylate, trade name Harmony

DPX-F6025, code name for 2(1[4-chloro-6-methoxypyrimidineyl)amino carbonyl]aminosulfonyl)benzoic acid ethyl ester, trade name Classic

EMS = Ethyl methanesulfonate

g $\mathrm{ai} / \mathrm{ha}=$ grams active ingredient per hectare

FW $=$ Fresh weight

$I_{50}=508$ inhibition relative to untreated controls

IBA $=1 \underline{H}-$ indole-3-butanoic acid

NAA $=1$-naphthaleneacetic acid

NMU $=\underline{N}-$ nitroso- $\underline{N}-$ methylurea

$S M=$ Sulfometuron methy 1

SU $=$ Sulfonylurea 


\section{List of Appendices}

Appendix

Page

1. Media composition . . . . . . . . . . . . . . . 92

2. Leo callus culture: Pretests to determine dose/response range for Classic and Harmony . . . . . . . . . . . 93

3. In vitro germination of outcrossed seeds of eight fertile lines on Harmony selection media $\left(10^{-5} \mathrm{M}\right)$. . . 94

4. Analysis of the effect of herbicide treatment on callus growth of six cell lines at 2 and 4 weeks . . . . . . 95

5. Analysis of the effect of herbicide treatment on 13 selected lines on height at week $0 /$ week $6 /$ and increase in height over this pericd - from indoor study . . . . . . . . . . . . . . . . . . 96

6.A Analysis of effect of three herbicide treatments and 12 selected lines on yield - from field study, 1989 . . 97

6.B Analysis of the effect of herbicide treatment on days to flowering (1989) . . . . . . . . . . . . . 98

6.C Analysis of the effect of herbicide treatment on days to pod maturity (1989). . . . . . . . . . . . . . 98

7. Analysis of ALS inhibition (as a percent of respective controls) of four genotypes at four treatment levels. . 99 
INTRODUCTION

Birdsfoot trefoil, Lotus corniculatus L. CV. 'Leo', a forage legume widely grown in the northeastern United States and Canada, has many unique qualities such as high tolerance to poor soil, long persistence, bloat safety, ind a forage quality comparable to alfalfa. However slow seedling growth, the inability to compete with weeds, coupled with a sensitivity to herbicides have all contributed to problems in establishing large stands (Hoveland et al., 1982). Wakefield and Skaland (1965) reported that weed control measures substantially increasea yield of trefoil compared to untreated stands. On the other hand several pre- and post-emergent broadleaf herbicides tested in trefoil stands cause severe yield reduction. A herbicide which is capable of controlling weeds and not adversely affecting trefoil would be of value. Unfortunately due to the high costs involved in research, testing, marketing and registration new herbicides are very expensive to produce. Machado et al., (1983) suggested one solution to this problem would be the development of cultivars with tolerance or resistance to already existing herbicides. A genetic tolerance for herbicides introduced into a trefoil cultivar would therefore be of economic value.

Sulfonylurea herbicides, the best known of which is chlorsulfuron (CS) sold under the trade name Glean, were developed by E.I. Du Pont de Namours and Co. to control 
broadleaf weeds in cereals. Important features or these herbicides include low application rates, a short half-life in soil and low mammalian toxicity (Levitt, 1953).

Chlorsulfuron acts by binding to and inactivating the acetolactate synthase (ALS) enzyme, inhibiting the biosynthesis of the essential branched-chain amino acids. DPX-M6316, trade name Harmony, is also reported to act on ALS (Sionis et al., 1985) and similar data were presented for chlorimuron ethyl, DPX-F6025, trade name Classic (Ray, 1985).

Since cell division and growth are inhibited by the sulfonylureas (Levitt, 1983), these herbicides can be used to select in vitro for resistant mutants. Genetically stable cs tolerant fertile plants have been isolated using cell culture techniques by Chaleff and Ray (1984) with tobacco and by Swanson et al., (1988) with Brassica napus $L$. The objectives of this study were to select for regenerants of Lotus corniculatus cv. Leo, tolerant to the herbicides Classic and Harmony using in vitro tissue culture selection techniques. In addition, to evaluate this resistance at the cellular, whole plant and biochemical levels. Since this work was initiated in 1987, Du Pont has informed us that they are discontinuing the development of the herbicide classic and that Harmony will be sold in Canada under the trade name Refine. 


\section{LITERATURE REVIEW}

\subsection{In Vitro Selection for Herbicide Resistance}

Herbicides are now extensively used to improve crop yields. However, the damage caused by soil residues in crop rotation programs and selective concentrations used for weed conzrol, have narrowed the usefulness of many herbicides to a limited range of crops, and for many crops suitable herbicides are still not available.

The high cost of producing, testing and marketing new herbicides has made the development of plants with tolerances to specific herbicides, already on the market, a feasible solution to these crop/herbicide interaction problems.

Furthermore, due to advances in plant biotechnology techniques, the development of resistant cultivars is now becoming increasingly possible and more far reaching. cell and tissue culture selection and gene transformation techniques are now employed for many species. In addition, an accumulated body of information of biochemical pathways of herbicides, along with an understanding of the different mechanisms involved in plant resistance, are now available.

Using cell culture techniques, it is possible to screen large populations of somatic cells for resistant variant cells in a limited amount of space and in a short time. The source of genetic variability can already be present in the original tissue, can be generated with the use of a mutagen or be 
randomly culture induced. Callus, suspension, and protoplast techniques have all been used in cell selection programs, each with their own advantages and limitations.

Moreover, the application of a selection pressure (i.e. an herbicide in the culture medium) during the selection procedure makes the screening more efficient by giving the variant cells of interest the selective advantage. Only however, if the character that is being selected for, operates at the cell level, and is also expressed in the whole plant, can selection using cell culture techniques be a useful tool. Metribuzin, for example, a highly effective herbicide on photosynthesizing seedlings, acts on the photosynthetic electron transport system. However, the herbicide was found to have no effect on callus culture growth and development (Ellis, 1978). Therefore, herbicides which also act at the cellular level, such as the sulfonylureas, are excellent candidates for in vitro selection programs, and recent research has demonstrated this (Chaleff and Ray, 1984; Saxena and King, 1988; Swanson et al., 1988).

\subsection{Somaclonal Variation}

It is now an accepted fact that genetic and cytogenetic variation occur frequently in somatic cells during in vitro growth and that this phenomenon can be exploited for breeding purposes. Somaclonal variation was first described by Larkin and Scowcroft in 1981. It is the variation seen among plants regenerated from cell culture. The exploitation of this 
variation as a source of useful mutants or for crop improvement has been reviewed extensively (Evans and Sharp, 1988; Larkin, 1987; Mitra, 1985; Chaleff, 1983)

The underlying mechanisms generating the variation are still not completely understood although several correlations and assumptions have been hypothesized. These include culture regimes such as subculture intervals, duration of culture, and media components, especially growth regulators. Genotype, ploidy, explant source and the differentiated state of the explant have all been cited as possible influencing factors. ploidy level in Crepis capillaris tends to be directly proportional to variation (Sacristan, 1971). Mode of regeneration, i.e. organogenesis or embryogenesis, has been indicated by several workers as an influential factor in somaclonal variation. Armstrong and Phillips (1988), in maize, and Bebeli et al., (1988) with rye, found fewer abnormalities in regenerants from embryogenic cultures compared to organogenic cultures. A correlation exists between regenerative capacity, duration in culture and chromosome stability (Murashige and Nakano, 1967).

\subsection{Cytological studies of Cells from Tissue Gulture}

Investigation of somaclonal variation at the cytological level has up until recently been limited. This is because most of the early tissue culture research has been confined to tobacco and carrot species (Sunderland, 1973). Both of these 
species are poorly suited to cytological studies due to their small and numerous chromosomes. As cell culture technology advanced, other species such as maize (Green and Phillips, 1975) and the small grains (Green, 1978) with their long history in cytogenetics, became available for study. There are also tissue culture protocols now available for Crepis capillaris $2 \underline{n}=2 \underline{x}=6$ (Sacristan, 1971), and Haplopappus gracilis $2 \underline{n}=2 \underline{x}=4$ (Mitra and Steward, 1961). With these advances the chromosomal basis of somaclonal variation and the mechanisms that may generate this variation are now being investigated (Lee and Phillips, 1988). It should be kept in mind however, that tissue culture induced variation is a reflection not only of chromosome changes but of a wide range of changes at the molecular level, such as point mutations, caused by mutagenic affects of chemicals in the medium (Shepard, 1981).

Variation in chromosome number and structure such as polyploidy, aneuploidy and chromosome rearrangements have all been identified in cell cultures from a wide variety of species. Bayliss (1980) has reported that of 55 species studied in detail, only 11 retained the same chromosome number in culture as in the parent plant. Polyploidy can be a result of chromosome breakage and reunion. Orton (1984) reported that chromosomal/genetic variability occurs more readily in cultured tissue of natural polyploids than in monoploids or diploids. He concludes that the polyploid cell line has a greater freedom to generate variant cell types such as those with chromosomes 
bearing duplications of "desired" genes.

Gene amplification has been described in several herbicide selection experiments. Using suspension culture selection for resistance to $i$-phoshinothricin, an inhibitor of glutamine synthase (GS), alfalfa resistant cells were characterized by a 4 to 11 fold amplification of a GS gene (Donn et al., 1984). Lee and Phillips (1988) citing Schimke (1986) suggest that gene amplification in response to chemical agents may be due to several mechanisms such as extrachromasomal replication, site specific integration of DNA from killed cells, unequal sister chromatid exchange or disproportionate replication.

other types of aberrations observed in cells from culture were the result of changes in chromosome structure and most of these rearrangements result in chromatin loss. Deletions ranging from $10 \%$ in maize (Lee and Phillips, 1988) to complete arm elimination in oat and triticale (McCoy et al, 1982; Armstrong et al., 1983 respectively) have been observed. Reciprocal translocations, where large segments are exchanged between nonhomologues, deletions, and inversions have been reported (Lee and Phillips, 1988). Each of these changes can have an effect on the plant phenotype.

Analysis of chromosome breakpoint locations suggest that these rearrangements usually involve specific chromosomes and specific chromosome regions, particularly those containing the highly repetitive sequences of heterochromatin. In Crepis capillaris (Sacristan, 1971) and Zea maize (Lee and Phillips, 
1988) $82 \%$ and $51 \%$ respectively, of the translocations involved NOR chromosomes which have large blocks of heterochromatin. In cultured cells and regenerants of maize, triticale, and oat, where telocentric chromosomes are seen at high frequencies, breakpoints generally occur in the heterochromatic areas around the centromere. Changes in euchromatic regions are not generally observed.

Lee and Phillips (1988) and MCCOY et al., (1982) suggested a possible mechanism that can trigger such genetic variation. It involves the interaction of two mitotic cycle events: late replicating heterochromatin and a deviation in the timing of the cell culture mitotic cycle. The combination of these events interferes with the completion of DNA synthesis. This in turn may result in bridge formation and breakage at anaphase and the possible activation of transposable elements. These transposable elements, once activated, may generate many mutations, which are characteristically unstable. Mcclintock (1983) suggested that the activation of transposable elements may be a response by the plant genome to imposed trauma and stress. Activation of transposable elements during the culture phase has been demonstrated in maize (Peschke et al., 1986)

\subsection{Herbicide Tolerance / Resistance - Epigenetic / Genetic} Variation

Many attempts to produce herbicide tolerant plants using in vitro selection have been made to date with varying degrees of 
success. While it is relatively easy to isolate resistant cell lines, obtaining resistant whole fertile plants has been much more difficult.

Tolerance at the cell level is not always stable and may be lost when the selection pressure is removed. If the tolerance does persist in the absence of the selection agent it must still be expressed in the regenerated whole plant. For many species regeneration is still difficult for normal plant cells, let alone selected variant cells, since karyotypic changes are a factor influencing the loss of organogenic capacity lorton, 1984). To demonstrate conclusively that the herbicide tolerance has a genetic basis, the tolerance must be transmitted to the selfed progeny of the regenerated plants. The altered phenotype can be classified as 'resistant' to normally lethal levels of the herbicide or 'tolerant', i.e. the plant can survive at sublethal levels as compared to the wild type (Gressel et al., $1978)$.

Unstable herbicide tolerance may be due to epigenetic events which develop in response to selection pressure and may be reversed when the pressure is removed. Epigenetic events reflect altered levels of gene expression resulting from abnormal operation due to culture conditions rather than from a true mutation of regulatory mechanisms (Chaleff, 1983).

Hughes (1983) suggested that instability can also be due to a very low or total absence of expression of the variant trait even though it may be present in the genome. This is because 
gene(s) for herbicide resistance may be differentially activa'ed, i.e. the mutation is expressed in cultured cells but not in the regenerated whole plant (Meredith and Carlson, 1982). Another possible explanation for this instability may be that certain kinds of genatic changes such as gene amplification or aneuplody are often not genetically transmitted from one generation to the next. Furthermore, resistance may be lost if plants are regenerated from chimeric callus composed of both resistant and sensitive cells. The sensitive cells may outgrow the resistant cells on non-selective media, and since these sensitive cells may also have increased organogenic capacity, a sensitive plant may be produced. For example the research of Singer and McDaniel (1985), was initially very promising. They originally isolated 51 glyphosate tolerant tobacco cell lines. However, after three years on selective medium only 18 retained their resistance. After 14 months on non-selective medrum all but six lost their tolerance. Only four glyphosate tolerant cell lines were regenerated and none of these plants were fertile.

\subsection{Sulfonylurea Herbicides}

Sulfonylureas are herbicides developed for control of broadleaf weeds as well as for some grasses in cereals and grain crops (Blair and Martin, 1988). These herbicides have many important features. They have high herbicidal activities at extremely low rates of application, expressed as $\mathrm{g} / \mathrm{ha}, 110$ to 40 $\mathrm{g} / \mathrm{ha}$ ) as opposed to most herbicides currently marketed, which 
are expressed as $\mathrm{kg} / \mathrm{ha}$ (Sweetser et al., 1982; Chaleff and Ray, 1984). This is the equivalent of one to two tablespoons of active ingredient per acre (Ray, 198\%). The soil half-life of the new generation of these herbicides (e.g. Harmony and Classic) is generally less than two months (Levitt, 1983). Harmony has a substitution of the phenyl ring of metsulfuron methyl with a thiophene which enhances metabolic degradation oy soil microbes (Beyer et al., 1987). A low mammalian toxicity $\left(L D_{50}\right.$ greater than $\left.5000 \mathrm{mg} / \mathrm{kg}\right)$ also make these herbicides a very ecolorically important group.

Extensive studies on the mode of action for the herbicide chlorsulfuron (CS) have been carried out by Ray (1982; 1984). Chlorsulfuron enters the plant via roots or foliage and is guickly translocated to the entire plant. Rapid growth inhibition was seen after CS application to corn, and in general, the sulfonylureas are classified as potent inhibitors of plant cell division (Levitt, 1983). Seeds treated with the herbicide germinate, however seedling growth is severely inhibited (Ray, 1980). Scheel and Casida (1985), using soybean cell cultures, reported rapid inhibition of cell growth but found no loss in cell viability. Other physiological processes such as photosynthesis, respiration, cell elongation, protein and RNA synthesis do nct appear to be affected by the recommended rates used for weed control, although damage was seen using much higher rates (Ray, 1980; 1982).

Morphological symptoms of sensitive plants include 
chlorosis, vein discoloration, terminal bud death and finally necrosis (Ray, 1980; 1982). Seeds within pods failed to develop and $50 \%$ reduction in pod formation was seen in Isatis tinctoria L. (King and Evans, 1983).

A strong inverse correlation was found between sensitivity of the plant to $C S$ and how fast the plant metabolises the herbicide (Levitt, 1983). Radioactive label studies have shown that after 24 hours, $97 \%$ of the radioactivity could be recove-ed as CS from sensitive plants such as sugar beet and cotton, whereas with wheat and oats, both considered tolerant plants, $95 \%$ of the radioactivity had been converted to a non-phytotoxic metabolite (Ray, 1985; Sweetser et al., 1982). Detoxification of the herbicide in tolerant crops is by hydroxylation of the phenyl ring, followed by conjugation with a plant carbohydrate (Sweetser et al., 1982).

Chaleff and Mauvais (1984) and Ray (1984) analyzed the resistance at the molecular level and have shown that growth inhibition in tobacco is caused by $C S$ binding to and inactivating the acetolactate synthase enzyme (ALS). The same mechanism exists for bacteria (LaRossa and Schloss, 1984), yeast (Falco and Dumas, 1985) and other higher plants such as Arabidopsis thaliana (Haughn and Somerville, 1986) and soybean (Sebastian et al., 1989). This binding results in the inhibition of the biosynthesis of isoleucine, leucine and valine, essential amino acids necessary for basic plant metabolic processes including cell division. Using cell cultures, Ray (1984) found 
that: $100 \mu \mathrm{M}$ of both valine and isoleucine alleviated growth inhibition and mitosis was blocked with cs concentrations of 28 to $280 \mathrm{nM}$ in the medium. The new sulfonylureas DPX-M6316 (trade name in U.S., Harmony; in Canada, Refine.) is also reported to act on ALS (Sionis et al., 1985) and similar data were presented for chlorimuron ethyl DPX-F6025 (trade name: Classic) by Ray $(1985)$

There is an accumulated body of evidence that SU resistance can be conferred to the plant in several ways. Experiments with Datura inoxia (Xiao et al., 1987) showed that the ALs gene had been duplicated in a resistant cell line. Thus, overexpression of ALS resuiting from an increased gene dosage conferred the increased tolerance. Blair (1988) contends that metabolism is likely the basis of tolerance, as ALS extracted frnm tolerant plants, wheat and oats, is as sensitive to CS inhibition as ALS from sensitive plants, such as peas and soybeans. However, Chaleff and Mauvais (1984), using tobacco suspension cultures, isolated CS resistant lines and found that the phenotype was inherited as a single dominant or semidominant mutation in the ALS gene, and that this single nuclear gene mutation was responsible for resistance exhibited at the whole plant level. The altered gene was characterized as being far less sensitive to inhibition by cs than the wild type. Similarly, Haughn and Somerville (1986) isolated from mutagenised $A$. thaliana seeds a modified form of the ALS gene and reported that resistance was successfully transferred and expressed in tobacco via 
Agrobacterium mediated transformation (Gabard et al., 1989). Thus it can be concluded that differential tolerance is in fact due to several physiological mechanisms such as translocation, detoxification and metabolic processes. However, resistance, such as that described by Chaleff and Mauvais (1984) and Haughn and Somerville (1986), is due to a genetic mutation of the ALs gene. The latter resistance has been characterised as 100 to 1000 fold greater than the wild type.

\subsection{Experimental Research - Sulfonylurea Herbicides}

The first reported successful experiments, where resistance was shown to be genetically transmitted to the progeny of cell culture regenerants were by the Chaleff research group.

Seven picloram resistant cell lines were isolated from tobacco suspension cultures plated on agar selection medium (Chaleff and Parsons, 1978). Resistant callus sections were regenerated and the putative resistant progeny were selfed and backcrossed. Four of these plants were found to be true mutants for picloram resistance. The numbers of resistant and sensitive progeny, resulting from selfing and backcrossing, were $3: 1$ and $1: 1$ ratios respectively. This established that the altered phenotype was a heterozygous individual in which resistance was conferred by a single dominant allele of a single gene mutation.

In a follow up experiment, this same group using two sulfonylurea herbicides, $C S$ and sulfometuron methyl (SM), isolated resistant tobacco mutants (Chaleff and Ray, 1984) and 
again established a genetic basis for the phenotypic change.

Using haploid tobacco suspension culture, cells were plated on solidified selection media. In one experiment they pretreated the cells with the mutagen NMU. Resistant cell lines were isolated and subjected to two more passages on selection media, each three weeks long. Resistant calli were then regenerated. Crosses of fertile plants were made and genetic analyses performed.

Segregation analysis showed that resistance was inherited as a single dominant or semidominant mutation in all cases. Linkage analysis of six resistant variants indicated that the mutations were located in two distinct regions. Callus from seed of resistant progeny was further tested on selection media and was resistant to $C S$, indicating seed heritability of the resistant trait.

One of the isolated mutants, 54 , was investigated in more detail. In its homozygous state it was found to be 100 fold more resistant to cS than the wild type, even though this line (S4) was selected on the basis of resistance to SM.

In a similar experiment, flax callus cultures were plated on selection medium containing CS (Jordan and McHughen, 1987). Shoots from surviving colonies were regenerated and whole fertile plants recovered from several CS resistant lines. Seeds of regenerants were germinated and callus was initiated from hypocotyls. The callus from several of the progeny was cs resistant, indicating seed heritability of the phenotype. 
Saxena and King (1988) using two SU herbicides, CS and SM, isolated resistant cell lines of Datura innoxia from cell suspension cultures. Cells were originally mutagenized with EMS, subcultured for 10 days to allow recovery of cells, followed by plating on agar solidified media containing lethal concentrations of CS or SM. Surviving clones were tested for resistance and found to be stable variants showing high, 100 to 1000 fold increases in resistance to the herbicides. An altered ALS enzyme, which is much less sensitive than the wild type enzyme, was cited as the basis for resistance.

Sebastian et al., (1989) using soybean in hydroponic culture, selected plants resistant to several sulfonylurea herbicides: CS, Classic, Harmony and DPX-L5300. Several generations of very large populations of soybean seeds were subjected to mutagenesis regimes using EMS or NMU. Followed by selection for resistance to $C S$, he was able to isolate several soybean mutants with increased resistance to SU herbicides. The mechanism of resistance was characterized as a reduced sensitivity of ALS to su inhibition.

In an earlier experiment sebastian and Chaleff (1987) isolated a soybean mutant, I-184, using a similar protocol, however, screening considerably fewer seeds and plants. This mutant only showed slight postemergence SU tolerance and only at concentrations sublethal to the wild type.

Using mutagenized microspores and microspore derived protoplasts of Brassica napus, Swanson et al., (1988) was able 
to select two lines tolerant to Cs levels $10-100$ times the wild type. Reciprocally crossed colchicine doubled progeny segregated according to semidominant patterns consistent with a nuclear mode of inheritance. Biochemical analysis of the two mutant lines showed an altered form of the ALS enzyme from the microspore derived mutant, while the als activity of the protoplast mutant was similar to the wild type.

\subsection{Experimental Research - Birdsfoot Trefoil (Lotus} corniculatus L. CV. Leo)

Birdsfoot trefoil has many unique qualities as a forage legume but there are problems establishing stands. On the positive side, it has high tolerance to poor soil and long persistence. It is bloat safe and has forage quality comparable to alfalfa. But slow seedling growth, inability to compete with weeds and sensitivity to herbicides make it a good candidate for developing an herbicide resistant cultivar. To date however, selection of herbicide resistant lines has been only marginally successful.

The first to work on this problem was Devine and his research group (1975). In a five year field program a variant, T-68, was selected from the cultivar 'Viking' that was substantially more tolerant to 2,4-D than the wild type. Swanson and Tomes (1980a) subsequently compared the in vivo and in vitro response of Divine's resistant cultivar T-68, and a susceptible Leo cultivar. They established that a correlation existed 
between the response of cultured cells and the whole plant to 2,4-D in both cultivars, as was also found to be true zor other species and other herbicides (Chaleff and Parsons, 1978; Gressel et al., 1978). From this experiment it was postulated that in vitro herbicide selection was a possible means to improve trefoil tolerance to $2,4-D$.

In a follow up experiment, callus anj suspension cultures were subjected to a series of culture passages using 2,4-D as the selection agent (Swanson and Tomes, 1980b). Leo callus was plated on agar selection medium and subjected to seven subculture periods of three weeks each. Likewise, suspension cell lines were isolated after two fourteen day passages in liquid selection medium, after which surviving cells were plated on solidified callus induction medium. Both these callus and suspension lines were regenerated and the shoots tested for resistance.

One callus and three suspension lines with improved 2,4-D tolerance were selected. However, none were found to be as resistant as the cultivar $T-68$. The intercross progeny of the tolerant lines did not show any differentia]. 2,4-D tolerance. Swanson and Tomes concluded that this may have been caused by high levels of inbreeding since all selections were initiated from the some original callus. The failure to isolate 2,4-D tolerant trefoil plants was also postulated to be due to the fact that trefoil is a cross-pollinated autotetraploid and following the sexual transmission of desired traits is seriously 
complicated by this feature (Raelson and Grant, 1989).

MacLean and Grant (1987), of McGill University, performed a similar experiment using trefoil suspension culture and the herbicides 2,4-D and CS. The regenerants were evaluated for herbicide resistance, pollen viability and chromosome number. One CS line showed some increased tolerance, however no sign of tolerance was seen in any of the 2,4-D selections at the level of $1.0 \mathrm{~kg} / \mathrm{ha}$. Pollen viability tests showed a high percentage of shrivelled pollen and a large variation in chromosome number was also observed. All the regenerants displayed lower fertility than the Leo control plants.

As of now, not much progress has been made in the selection of herbicide resistant plants of Lotus corniculatus. The development of such a cultivar still remains to be accomplished. The achievement of a resistant cultivar would be of considerable economic benefit. 


\section{MATERIALS AND METHODS}

\subsection{Culture Procedure}

\subsection{A Media Preparation}

The protocols followed for media formulation are based on those described by Gamborg et aI., (1968) for B5 medium and Murashige and Skoog (1962) for MS medium (Appendix 1). B5M medium (Swanson and Tomes, 1980a), a modified form of B5, with increased levels of $\mathrm{CaCl}_{2} \cdot \mathrm{H}_{2} \mathrm{O}(440 \mathrm{mg} / \mathrm{L})$ and $\mathrm{MgSO}_{4} \cdot 7 \mathrm{H}_{2} \mathrm{O}(370 \mathrm{mg} / \mathrm{L})$ was also used. B5 and B5M media were prepared and frozen in 100 $\mathrm{mL}$ aliquots of $10 \mathrm{X}$ concentration. As required, $100 \mathrm{~mL}$ of stock was thawed, growth regulators and sucrose were added, the $\mathrm{pH}$ was adjusted, agar added and the medium made to volume with double distilled water $\left(\mathrm{DDH}_{2} 0\right)$. One litre of medium was autoclaved for $20 \mathrm{~min}$ at $121^{\circ} \mathrm{C}, 10.35 \times 104 \mathrm{~Pa}$.

For MS medium, micronutrients and vitamins were prepared and frozen in $100 \mathrm{~mL}$ aliquots of $100 \mathrm{x}$ concentration (Stock $\mathrm{B}$ ). One hundred $\mathrm{mL}$ of thawed stock $\mathrm{B}$ was added to a two litre solution of macronutrients prepared at a $5 \times$ concentration and frozen in $100 \mathrm{~mL}$ aliquots (Stock A). As required, $100 \mathrm{~mL}$ of stock A was brought up to a volume of $500 \mathrm{~mL}$ with $\mathrm{DDH}_{2} \mathrm{O}$ and treated as described above.

\subsection{B Callus Initiation}

Seeds of birdsfoot trefoil (Lotus corniculatus cv. Leo) were obtained from the Emile Lods Agronomy Research Station at 
Macdonald Campus of McGill University. The seeds were scarified in liquid nitrogen to improve germination, (personal communication with J.V. Realson) after which all subsequent procedures were performed aseptically in a laminar air-flow hood. Seeds were surface sterilized in 708 ethanol for three min followed by $30 \mathrm{~min}$ in 508 commercial bleach. This was followed by three rinses in sterile $\mathrm{DDH}_{2} \mathrm{O}$. Seeds were plated on $25 \mathrm{~mL}$ of B5 solidified medium (Appendix 1) in $100 \times 60 \mathrm{~mm}$ plastic petri plates and placed in the dark for 5 to 10 days.

Callus was initiated from hypocotyl sections, five $\mathrm{mm}$ in length, placed onto $25 \mathrm{~mL}$ of B5M callus induction media in 100 x $60 \mathrm{~mm}$ plastic petri plates. Cultures were incubated in a growth room held at $25^{\circ} \mathrm{C}$ with a 16 hour photoperiod and a light intensity of approximately $29 \mathrm{molm}^{-2} \mathrm{~s}^{-1}$ of cool white florescent light. Subcultures were carried out at monthly intervals.

\subsection{Selection for Resistance}

\subsection{A Selection 1 - Using callus Culture of Birdsfoot Trefoil} For the selection media, DPX-M6316, (trade name Harmony) and chlorimuron ethyl, DPX-F6025 (trade name Classic) were obtained from E.I. Du Pont de Nemours and Co. as $80 \%$ and 25\% wettable powders, respectively. Stock solutions of Harmony and Classic were freshly prepared before each experiment and filtersterilized using a disposable Nalgene $0.20 \mu \mathrm{m}$ filter. Appropriate aliquots were incorporated into autoclaved, B5M 
medium just prior to dispensing when the medium had cooled (Table 3.1). These selection media were dispensed at $25 \mathrm{~mL}$ per plastic petri dish.

Pretests were performed to find the appropriate levels of herbicides to use for the callus selection procedure (Appendix 2). A dose-response experiment, with respect to growth inhibition, was set up for each herbicide in a complete randomized design with three replications (petri dishes) and seven concentrations. Ten pieces of Leo callus, weighing a total of $0.5 \mathrm{~g}$ per petri plate, were tested on selection media containing $10^{-8}$ to $10^{-3} \mathrm{M}$ of the herbicides Harmony or Classic at 10 fold increments, plus a control with no herbicide. Cultures were incubated in a growth chamber and weighed after two weeks. In this way a dosage range was chosen that was just above complete growth inhibition but not lethal.

Resistant cell lines were selected by using the same procedure as above (Fig. 1). Ten pieces of Leo callus per plate were transferred to selection media supplemented with increasing increments of the herbicides Harmony or Classic (Table 3.2). There were six passages, each lasting 14 days. Based on visual observations, only the most viable calli parts (i.e. green and friable) were transferred to the next (higher) selection level. Cytotoxic effects were measured after each passage by taking the fresh weight (FW) of the callus with a Mettler H-20 balance. Five petri dishes of each treatment (control, herbicide incorporated) were arranged in a complete randomized design and 
each passage analyzed separately using standard ANOVA procedure.

\subsection{B Selection II - Using SHOOTS Regenerated from Selection 1}

After 12 weeks of in vitro herbicide exposure, surviving callus sections from the last two subcultures of selection $I$, (Table $3.1 ; 10^{-6} \mathrm{M}$ and $2.5 \times 10^{-6} \mathrm{M}$ ) were transferred to shoot induction medium (B5M medium containing $0.5 \mathrm{mg} / \mathrm{L} \mathrm{BA}$; MacLean and Grant, 1987; Appendix 1) and incubated under the same conditions as above. Subcultures were performed at four week intervals until the regenerated shoots were approximately two $\mathrm{cm}$ in length. Due to an excessively high number of shoots regenerated, a second selection procedure was performed.

Shoots, from all three treatments (Harmony, Classic and control), 1-2 cm in length, were aseptically arranged in rows in three $20 \times 35 \mathrm{~cm}$ pyrex baking dishes, each containing $750 \mathrm{~mL}$ agar selection medium $\left(10^{-6} \mathrm{M}\right.$ Harmony or Classic) or control medium (Fig 2). Thus, each pyrex dish (containing one of the three media) was filled with shoots regenerated from all three treatments. The shoots in the pyrex dishes were incubated for 14 days.

Surviving putative resistant shoots were then rescued from the in vitro herbicide screening procedure and transferred to 30 mL glass culture jars containing solidified B5M media with 0.2 mg/L NAA for root induction. Whole plantlets were acclimatized in a mist frame for two weeks and transplanted to $75 \mathrm{~cm}$ pots with Pro-mix (a commercial mixture containing $3: 1: 1$ peat, 
perlite, vermiculite) and placed in a growth chamber. The growth chamber was set for ambient day and night temperatures of $22^{\circ} \mathrm{C}$ and $18^{\circ} \mathrm{C}$ respectively, with an $16 \mathrm{~h}$ photoperiod. At the same time, Leo seeds, (taken from the same population as the seeds used for callus initiation), were planted, so that they would achieve the same level of maturity at approximately the same time as the regenerants, to act as controls.

\subsection{Selection III - Using PLANTS Surviving Selection II}

At the three-leaf stage the seedling controls (A), control regenerants from (non-herbicide) in vitro selection (B), and putative herbicide resistant regenerants from selection media (C) were foliar-sprayed in a Research Instrument Manufacturing Company Spray Chamber (Guelph, Ontario) for further selection. Application to foliage was with a teejet full-cone nozzle (TG $0.7)$ calibrated to deliver $500 \mathrm{~L}$ ai/ha solution of the appropriate herbicide concentration. Plants were visually rated, 1 to 10 ; [1, dead; 2, recovery not possible; 3 , stunted and complete apical death; 4, severe necrosis of meristems, recovery doubtful; 5, yellowing and beginning of apical necrosis; 6, yellowing, but will recover; 7, apical meristems light green and plant stunted; 8, green and more stunted than 9; 9, green and slightly stunted; 10, no damage] for phytotoxicity at weekly intervals after treatment. Even though the rating scheme and in vivo dosagelresponse for Leo wild type plants were established, spraying was repeated several times with increasing doses in the 
range prescribed in the Du Pont work manual (1987), to cull the plants and select those with increased tolerance levels. At each selection stage the plants were coded so that their origin and selection route could easily be determined. 
Table 3.1

Herbicide Concentrations Used in Selection I: CALLUS Level

\begin{tabular}{|c|c|c|c|}
\hline Passage & $\begin{array}{l}\text { Selection } \\
\text { media conc. } \\
\left(\times 10^{-7}\right) M\end{array}$ & $\begin{array}{l}\text { Herbicide } \\
\text { stock used } \\
\text { for } 125 \mathrm{~mL}\end{array}$ & $\mathrm{~B} 5 \mathrm{M} \mathrm{mL}^{*}$ \\
\hline 1 & 1.0 & 0.25 & 124.75 \\
\hline 2 & 2.5 & 0.62 & 124.38 \\
\hline 3 & 5.0 & 1.25 & 123.75 \\
\hline 4 & 7.5 & 1.87 & 123.13 \\
\hline 5 & 10.0 & 2.50 & 122.50 \\
\hline 6 & 25.0 & 3.12 & 121.88 \\
\hline
\end{tabular}

* The B5M media used had nutrients for $125 \mathrm{~mL}$. Volumes were brought up to $125 \mathrm{~mL}$ with aliquots of herbicide stock solution of $10^{-4} \mathrm{M}$ (Classic or Harmony) for each treatment, and dispensed into five, $100 \times 60 \mathrm{~mm}$ petri plate. Five control plates without herbicide were prepared at the same time. 
Table 3.2

Herbicide Concentrations Used for Selection III: PLANT Level

\begin{tabular}{lll}
\hline Test & Harmony $(g$ ai/ha $)$ & Classic g ai/ha \\
1 & $17.5^{*}$ & $11.68^{*}$ \\
2 & $30.63^{*}$ & $17.42^{*}$ \\
3 & 43.76 & 20.24 \\
4 & - & $23.16^{* *}$ \\
5 & - & 46.32 \\
\hline
\end{tabular}

* Range of recommended field concentrations

** At this point 9 cuttings of each of the most tolerant 40 plants were established in three $6 \mathrm{~cm}$ pots.

Table 3.3

Herbicide Concentrations used in Growth Chamber and Field Tests

r

Treatment Level 1 Level $2^{*}$ Level $3^{*}$
Harmony
0.0
$43 \cdot 76^{* *}$
87.52

$\begin{array}{llll}\text { Classic } & 0.0 & 23.16^{* *} & 46.32\end{array}$

* g ai/ha. ** Concentrations used in growth chamber tests. 


\subsection{Evaluation of Resistance}

\subsection{A Callus Test of Putative Mutant Selections}

Callus was initiated from putative resistant regenerated lines of Harmony using 5 to $10 \mathrm{~mm}$ stem sections taken from the top three $\mathrm{cm}$ of the growing shoots. Explants were rinsed under running water, surface sterilized in a $20 \%$ commercial bleach solution for $20 \mathrm{~min}$ followed by three rinses in sterile $\mathrm{DDH}_{2} \mathrm{O}$. stem sections were plated on callus induction medium as described in section 3.1.B. It was found, however, that for most selections growth was slow (as compared with Leo), whereas for other lines, callus establishment was not seen even after several weeks. Therefore, after six weeks the explants were transferred to MS medium (Appendix 1) supplemented with $0.4 \mathrm{mg} / \mathrm{L}$ 2,4-D. Cytotoxicity was tested as described above (section 3.2.A) on those lines that produced enough callus. Six pieces of each callus line weighing a total of $200 \mathrm{~g}$ were plated on selection medium with $10^{-5} \mathrm{M}$ Harmony, incubated for two weeks, weighed, replaced on fresh selection medium and reweighed again after two weeks. A completely randomized design, consisting of three petri dishes per cell line per treatment was used for fresh weight measurements at two and four weeks intervals and analyzed using standard analysis of variance procedures.

\subsection{B Growth Chamber Analysis}

To test and characterize the level of resistance of putative mutant selections, four cuttings were made of all 12 
surviving Harmony lines. Shoot tips four $\mathrm{cm}$ in length were dipped in $0.1 \%$ IBA, placed into $40 \mathrm{~mm}$ plastic cell packs filled with vermiculite and put in a mist frame for root development. Leo control plants grown from seed were treated similarly. At the three-leaf stage, when the cuttings were approximately six $\mathrm{cm}$, the plants were foliar-sprayed with herbicide (Table 3.3), using the same apparatus as described in section 3.2.C. The plants were arranged in a complete randomized design consisting of three separate pots per plant lines, scored visually for phytotoxicity and the height measured at weekly intervals for six weeks. Data for week 0 , week 6 and height increase over this period were analyzed using standard analysis of variance procedures followed by multiple comparisons using Duncan's Multiple Range test.

\subsection{C.i. Field Analysis I (1989)}

Eleven putative resistant cell line selections from each herbicide treatment, plus Leo seedlings as controls, were fieldtested. Twelve cuttings from each line, were acclimatized in a cold frame. Nine of the 12 cuttings that were most similar in size were transplanted to the field. On May 30, 1989, all plants 25 days old and approximately $10 \mathrm{~cm}$ high were transplanted into a $12 \times 30 \mathrm{~m}$ field plot at the Emile A. Lods Agronomy Research ntre. The experimental design was a two factor factorial arrangement of a randomized complete block design with 3 replications. The two factors were the 12 cell lines at three levels of herbicide treatments. Plant were spaced one meter 
apart. Ten days after transplanting, each plant was sprayed with the appropriate herbicide or water (Table 3.3), using a hand operated plant mister which had been previously calibrated. Two similar experiments were run, one for putative mutants from Harmony and one for Classic. Border plants surrounded each of the plots and subplots to prevent herbicide drift from the spray. The plot was mechanically and hand weeded as needed.

Data were collected for:

a) Phytotoxicity - at four day intervals for three weeks by visually ranking injury (using the scale described in section $3.2 . C)$.

b) Days to flowering and pod maturity - When at least two open flowers per plant were seen, and two fully expanded green pods had developed.

c) Dry weight yield and height after 3 months - Plants were cut at the crown and dried in a corn dryer at $24^{\circ} \mathrm{C}$ for four days and weighed. Height was measured in the field from the crown to the tip of the average shoot.

d) Pollen stainability - Flowers (3/plant) just prior to anthesis were collected from all 12 Harmony selections from the field and scored for pollen stainability. One hundred pollen grains per flower, mounted temporarily in fast green and lactophenol, were scored at a magnification of $400 \mathrm{x}$. Pollen grains which stained green and appeared plump were considered viable, whereas unstained and shrivelled pollen grains were considered non-viable (Grant et al. 1962).

Analysis of variance was performed on data collected for 
yield, height, days to flowering and days to pod deveiopment. where significant interaction effects between cell lines and herbicide treatments were seen, orthogonai contrast analyses were performed.

\subsection{C.ii. Field Analysis II}

The following summer, 1990, seeds that had been previously screened on $10^{-5} \mathrm{M}$ Harmony selection media from line $\mathrm{H} 1-1, \mathrm{H} 5-1$, H5-10 and Leo control, were tested. A randomized complete block design in a split plot arrangement was used. The main plots units consisted of the four cell lines and four levels of herbicide treatment, $0.0,30.0,60.0$, and $100.0 \mathrm{~g} \mathrm{ai} / \mathrm{ha}$, were subplot units, with five blocks as replications. The plants were arranged and treated as in section 3.3.B.i. The Friedman test for non-parametric data was used for phytotoxicity ratings analysis.

Selected line H4-10 (along with LeO, H5-1 and H5-10) was tested in a randomized complete block design with 10 blocks. To establish whether the yield increase noted in line H4-10, from 1989 field trials, was associated with other phenotypic traits, various qualitative and quantitative measurements were taken; Quantitative measurements: yield, height, central leaflet length and width, flower bract length and width, internode length, flower length and ovary length. Data were analyzed with the general linear model analysis for a randomized complete block. design followed by the LSD test.

Quantitative measurements such as flower color, keel tip color, 
bud color, pod shape and growth habit were also taken.

\subsection{Cytogenetic Studies}

Chromosome numbers were determined for all 12 Harmony lines that had been field tested (1989). Cuttings were prepared as above and grown in a mist chamber. After 15 days, root tips were collected and pretreated for two hours in a $0.002 \mathrm{M} 8$ hydroxyquinoline aqueous solution and then fixed for 24 hours in a solution of $3: 1,95 \%$ ethanol and glacial acetic acid, respectively. Fixed root tips were hydrolysed in $1 \mathrm{~N}$ hydrochloric acid at $60^{\circ} \mathrm{C}$ for $10 \mathrm{~min}$, followed by staining in leucobasic fuchsin for four hours, according to the Feulgen technique (Darlington ard La Cour, 1976). Stained root tips were treated with 48 pectinase aqueous solution for four hours to facilitate maceration, rinsed with $\mathrm{DDH}_{2} \mathrm{O}$, placed in a $70 \%$ ethanol solution and stored in a refrigerator. Slides were prepared by squashing root tips in a drop of 458 acetic acid and adding a coverslip. Permanent slides were prepared by freezing the slides to remove the coverslip then after one change in 958 and two changes in absolute alcohol they were mounted in Permount with a clean coverslip. Photographs were taken with a Zeiss photomicroscope.

\subsection{E Acetolactate Synthase Enzyme Assay}

ALS activity was measured using the method described by Chaleff and Mauvais (1984) with modifications by Swanson et al. (1988) and J. Granger (Ag, Canada; personal communication). 
The protocol for the assay was as follows:

\section{Extraction}

1. In a mortar and pestle $1 \mathrm{~g} F W$ of the youngest fully expanded leaves, randomly picked from 10 cuttings of each line, were homogenized in $3 \mathrm{~mL}$ extraction buffer containing:

$$
\begin{aligned}
& 100.0 \mathrm{mM} \mathrm{KH} \mathrm{KHO}_{4} \quad \mathrm{pH} 7.5 \\
& 0.5 \mathrm{mM} \mathrm{MgCl}_{2} \cdot 6 \mathrm{H}_{2} \mathrm{O} \\
& 1.0 \mathrm{mM} \text { Na pyruvate } \\
& 0.5 \mathrm{mM} \text { thiamine pyrophosphate (TPP) } \\
& 10.0 \mu \mathrm{M} \text { flavine - adenine dinucleotide (FAD) } \\
& \text { with the addition of } 250.0 \mathrm{mg} \text { polyclar }
\end{aligned}
$$

2. The solution was centrifuged in a Beckman microfuge for 20 min at $12500 \mathrm{rpm}$.

\section{Purification}

1. Acetolactate synthase was precipitated from the supernatant with an equal volume of saturated ammonium sulfate, and was left to stand for one hour.

2. The mixture was centrifuged for $5 \mathrm{~min}$ in a microfuge.

3. The pellet was resuspended in extraction buffer base (which consists of the first three ingredients of the extraction buffer) and desalted by pipetting the mixture into a sephadex G25 column (Pharmacia PD-10) equilibrated with $20 \mathrm{~mL}$ of the same buffer. All the above operations were carried out at $4^{\circ} \mathrm{C}$.

\section{Enzyme Assay}

1. In a $1.5 \mathrm{~mL}$ eppendorf tube, $400 \mu \mathrm{L}$ reaction buffer was added consisting of: $65 \mathrm{mM} \mathrm{KH}_{2} \mathrm{PO}_{4} \quad \mathrm{pH} 7.5$ 
$10 \mathrm{mM} \mathrm{MgCl}_{2}$

$0.25 \mathrm{mM}$ TPP

$23 \mu M$ FAD

$100 \mu \mathrm{L}$ column eluent was added plus $0.5 \mathrm{~mL}$ of the appropriate concentration of herbicide. Assays were carried out in a final volume of $500 \mu \mathrm{L}$ and incubated for 90 minutes at $30^{\circ} \mathrm{C}$.

2. The reaction was stopped by adding $200 \mu \mathrm{L}$ of $6 \mathrm{~N} \mathrm{H}_{2} \mathrm{SO}_{4}$ to each tube, and incubated for 10 min at $55^{\circ} \mathrm{C}$ to achieve complete conversion of acetolactate to acetoin.

3. To the acidified reaction mixture was added:

$$
\begin{aligned}
& 150 \mu \mathrm{L} 50 \% \mathrm{NaOH} \\
& 150 \mu \mathrm{L} 0.5 \% \text { creatine } \\
& 150 \mu \mathrm{L} 5.0 \% \text { a naphthol (fresh in } 2.5 \mathrm{~N} \mathrm{NaOH} \text { ) }
\end{aligned}
$$

The mixture was incubate at $55^{\circ} \mathrm{C}$ for $10 \mathrm{~min}$ to accelerate color development, then centrifuged in a microfuge at 12,500 rpm for 5 min.

4. Acetoin was measured by reading the absorbance at $525 \mathrm{~nm}$. Final concentrations of $0,1,10,100,1000 \mathrm{ug} / \mathrm{L}$ of DPX-M6316 were used. Protein concentrations were measured using the BioRad Protein Assay reagent with bovine serum albumin as a standard. All measurements were the average of four independent determinations at each herbicide concentration and expressed as the percent of uninhibited ALS activity (to coxrect for possible differences in the amount of enzyme extract present for each line). The $I_{50}$ was defined as the herbicide concentration needed to inhibit ALS activity by 50 percent as compared to respective controls. 


\subsection{F In Vitro Seed Germination Trials}

A successful assay was developed to screen for tolerance levels of seeds collected from the field trials. It was found that by plating surface sterilized, presoaked seeds on selaction medium (with $10^{-5} \mathrm{M}$ Harmony), Leo control seeds germinated and their cotyledons opened normally, but true leaves did not develop and root growth ceased after one week (when nutrients present in the seed were no longer available).

A trial using seeds from each of the seven fertile lines, collected from the outcrossed field plants, was set up to screen for Harmony resistance and using the above procedure. Sterilized seeds were plated on four petri plates/line (20 seeds/plate), containing $10 \mathrm{~mL}$ of the selection medium, left to germinate in the dark, at room temperature for three days and then placed to in a growth room to develop (under the conditions mentioned in section 3.1.B). Leo seeds, also from the field test, were used as the standard for comparison. This test was performed three times and a total of approximately 100 seeds/1ine were scored for trifoliate leaf development two to three weeks after germination. Data were collected on the number of germinated seeds with true secondary leaf growth. 


\section{RESULTS AND DISCUSSION}

\subsection{SELECTION FOR RESIS'CANCE}

\subsection{A. Selection I}

The effect of selection media on callus growth is summarized in Table 4.1. Callus fresh weight data were analyzed using the ANOVA procedure for a completely randomized design. In most cases, the herbicide treatment significantly inhibited callus growth. An exception was the herbicide classic, passage four, in which callus growth was not inhibited. However by the next passage (5), it can be seen that this problem was subsequently rectified with the addition of $1-2$ drops $1 \mathrm{~N} \mathrm{NaOH} / \mathrm{L}$ to the herbicide media, thereby bringing the herbicide into solution. The selection procedure was discontinued at passage 6 , where a marked decrease in cell division was seen and the herbicide treatment was observed to be lethal to a majority of cultured cells. The callus at this stage was almost entirely brown with some small greenish areas surviving the treatment (Fig.1). These areas were excised and placed on regeneration medium. Shoot regeneration occurred after one-to-two months, at approximately the same rate $(65 \%-80 \%)$ for control and selected lines (Fig. 1b). 
Fig.1a. (top)

Leo callus after two weeks or. Harmony Classic $\left(10^{-6}\right.$ M) selection media and control nedium.

1b. (bottom)

Early shoot development after one month of growth on B5M supplemented with $0.2 \mathrm{mg} / \mathrm{L}$ NAA . 


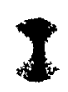

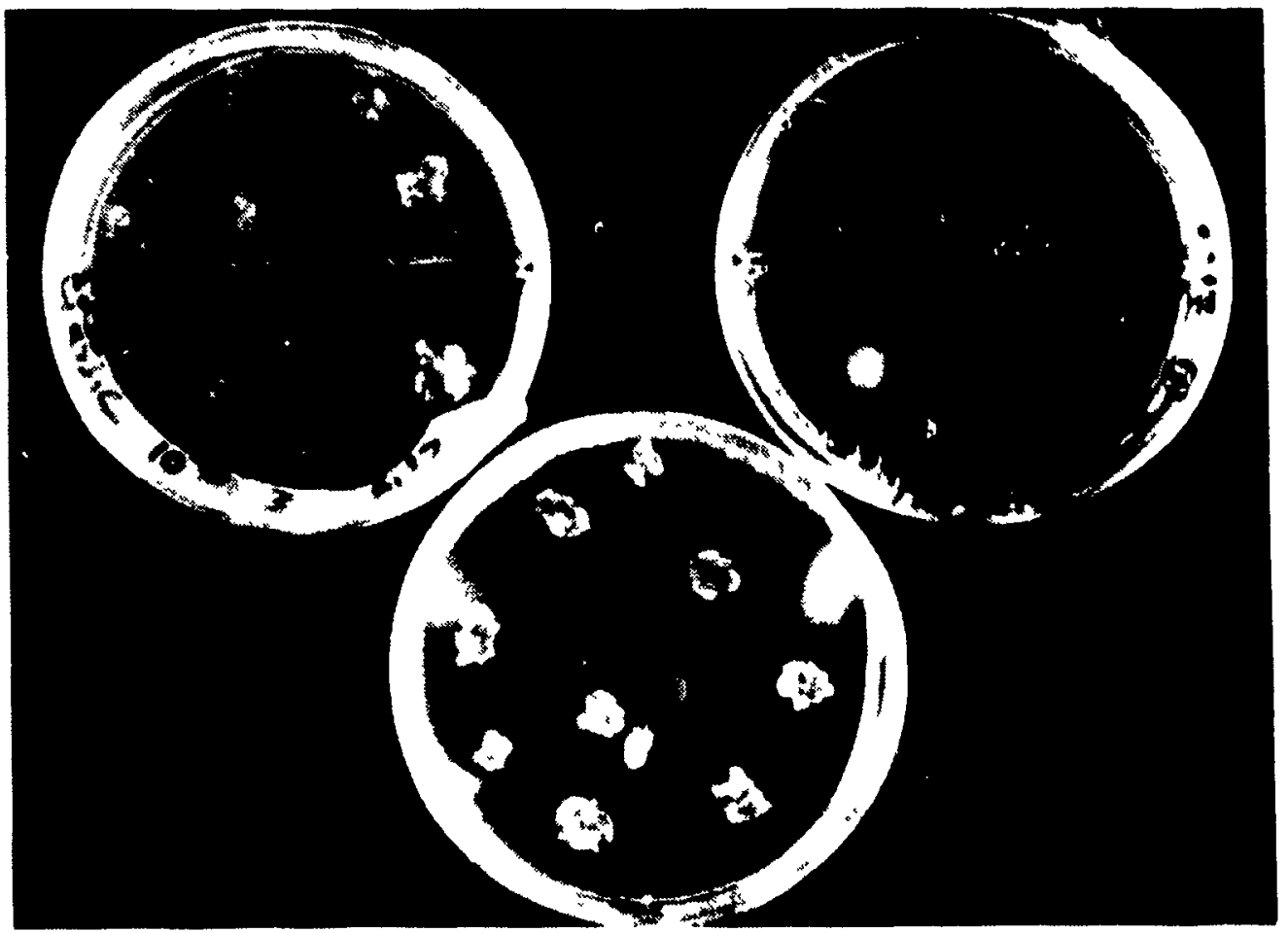

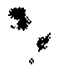
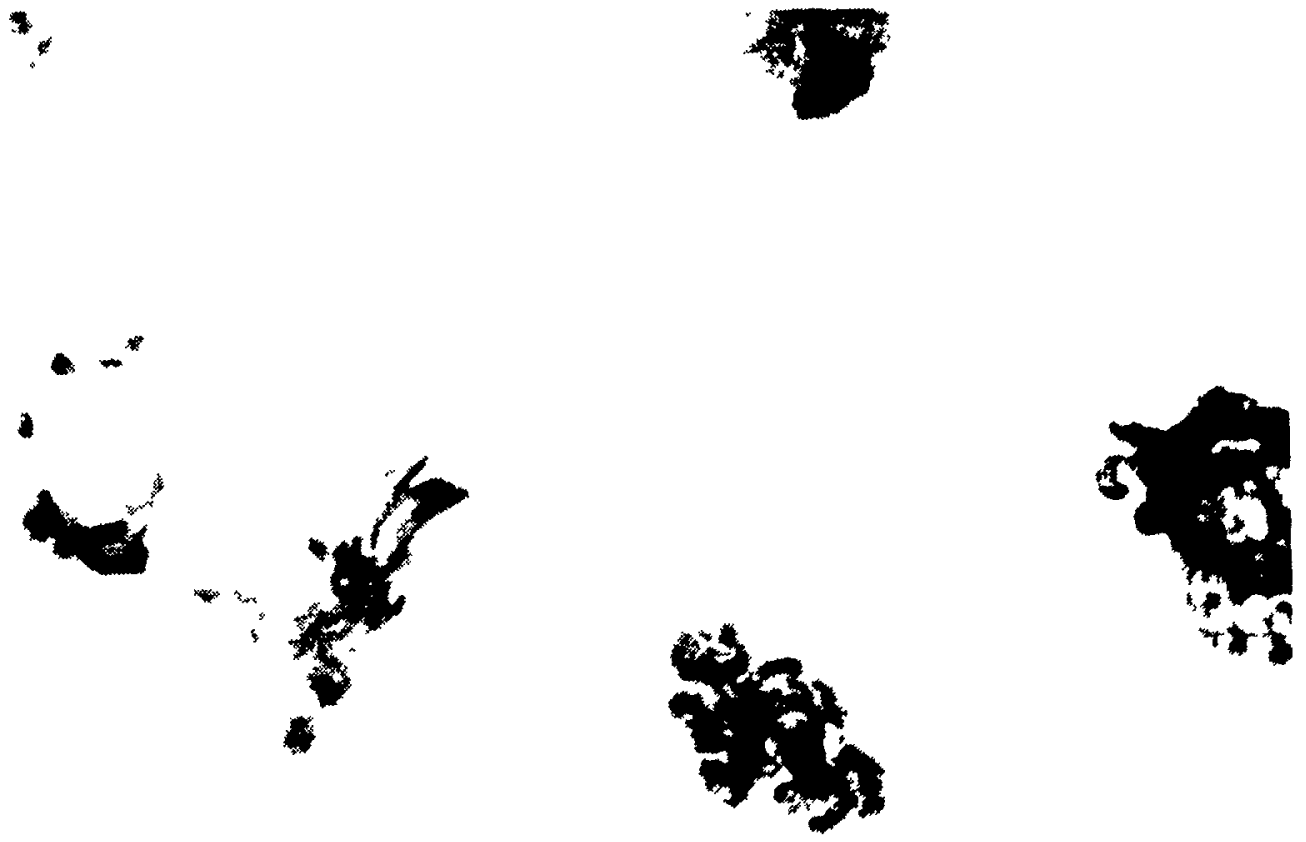
Table 4.1 Means of callus fresh weight $(g)$ after two weeks on B5M medium (control) or selection media, supplemented with Harmony or Classic.

Selection I

Callus Weight $(g)$

\begin{tabular}{llll}
\hline Passage & Control & Harmony & Classic \\
\hline 1 & $2.240 \mathrm{a}^{*}$ & $1.372 \mathrm{~b}$ & $1.458 \mathrm{~b}$ \\
\hline 2 & $2.508 \mathrm{a}$ & $1.578 \mathrm{~b}$ & $1.896 \mathrm{~b}$ \\
\hline 3 & $2.728 \mathrm{a}$ & $1.264 \mathrm{c}$ & $2.386 \mathrm{~b}$ \\
\hline 4 & $2.270 \mathrm{a}$ & $1.384 \mathrm{~b}$ & $2.140 \mathrm{a}$ \\
\hline 5 & $2.173 \mathrm{a}$ & $0.895 \mathrm{~b}$ & $0.975 \mathrm{~b}$ \\
\hline \hline
\end{tabular}

+ Herbicide concentration for each passage described in Table 3.1 .

* Means followed by different letters, in each passage only, are significant at the 0.05 probability level according to Duncan's Multiple Range test. 


\subsection{B. Selection II}

The number of shoots regenerated from excised callus areas was very high. Approximately 400 shoots, $3 \mathrm{~cm}$ high, were therefore screened again on selection media (Fig. 2a,b,c). This selection procedure which was devised in our laboratory, makes in vitro selection more time and space efficient. One can therefore select for the trait at the shoot stage before root induction and before transplanting to the greenhouse.

Because of the strong selection pressure exerted on the callus tissue in selection $I$, it was quite unexpected when so many shoots regenerated from relatively tiny clumps of callus tissue, and that such a high percentage of the regenerated shoots were not resistant (Table 4.2). It has been suggested that as callus is an aggregate of plant cells it is very likely that a wild type cell(s) could be protected by nearby resistant cells. Regenerating shoots can arise from either cell type in the chimeric cluster, with the wild type cells having the competitive advantage, since there tends to be selection for normal karyotypes in plant regeneration (Torrey 1967). Alternatively, epigenetic changes may be responsible for the initial resistance response which is subsequently lost in regeneration or with the removal of the selection agent (Chaleff $1981,1983)$

Shoots regenerated from callus selection media supplemented

with $2.5 \times 10^{-6}$ M Harmony, (passage 6) from selection I had the highest survival rate in selection II (Table 4.2). 
Fig. 2a. (top) Regenerated shoots, from selection $I$, being placed on control and selection media.

2b. (middle) Close-up of shoots on selection media after one week of growth.

2c. (bottom)

Same as $2 \mathrm{a} .$, after two weeks of growth. 

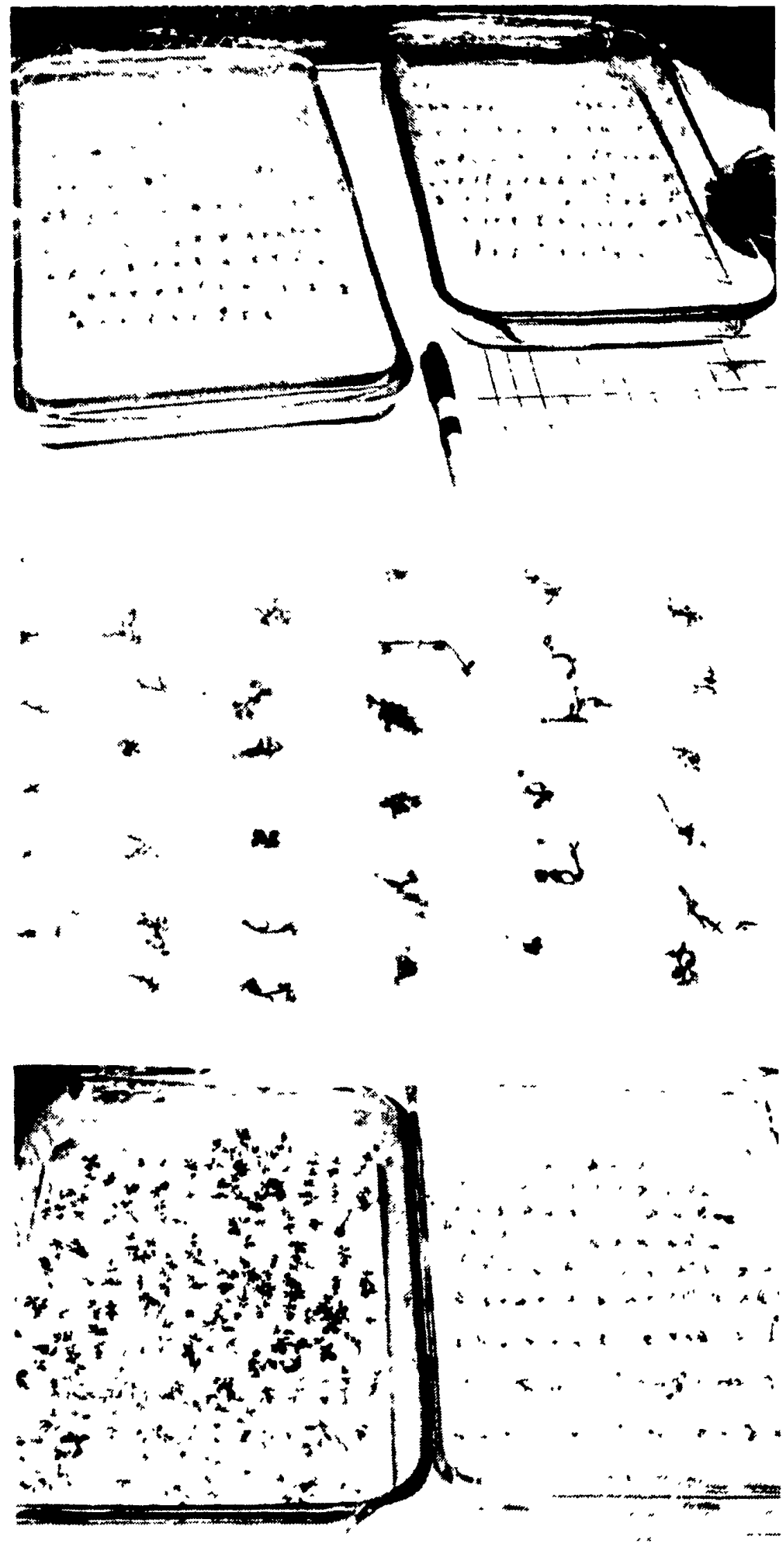
Fig. 3a. (top) Acclimatized plants (controls) that had been rooted on media with $0.02 \mathrm{mg} / \mathrm{L}$ NAA (left) and no growth regulators (right).

3b. (bottom)

Regenerated plants being treated in Spray Chamber. 

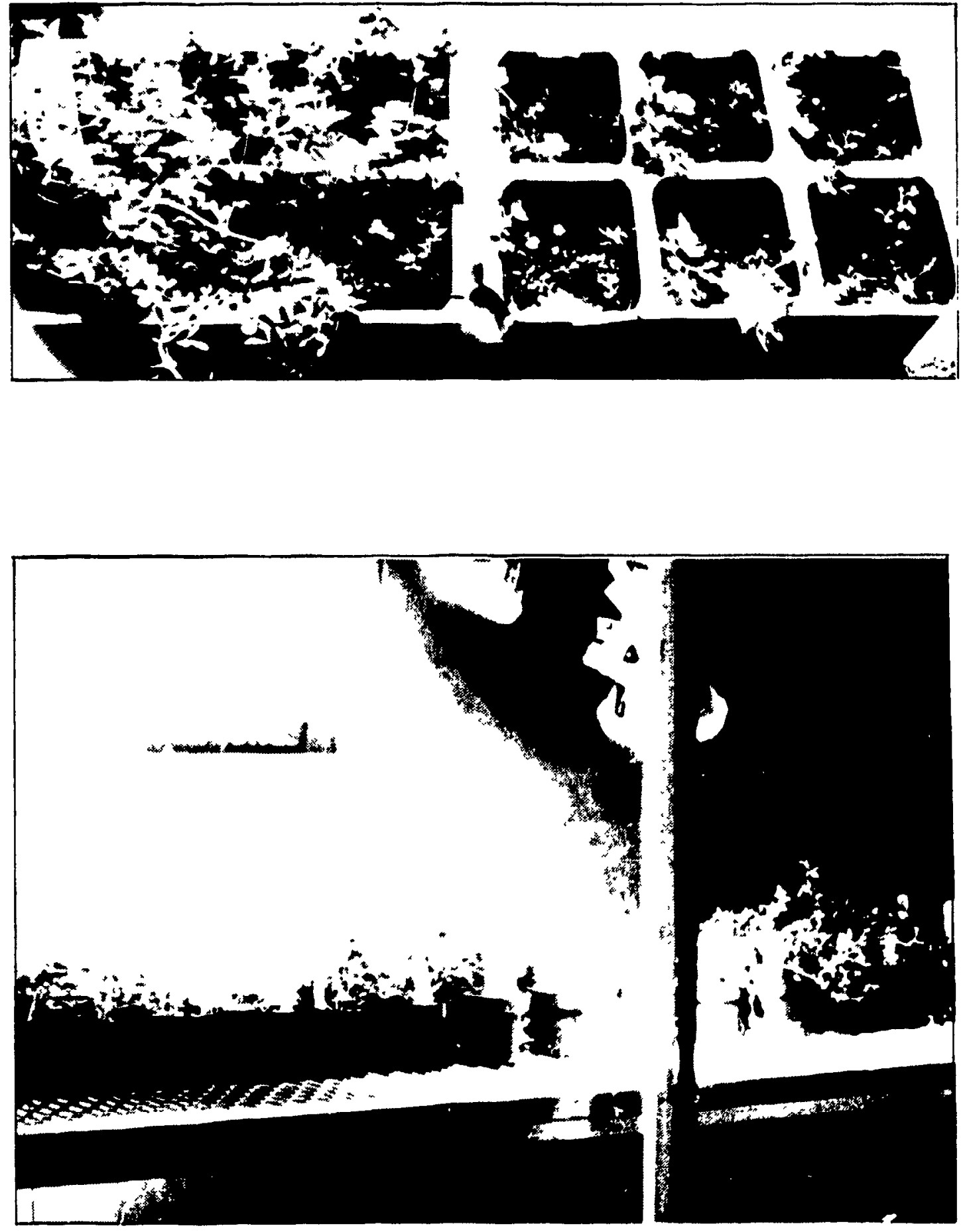
After this selection step the shoots were placed on solidified rooting medium. Preliminary tests comparing root initiation on media with $0.2 \mathrm{mg} / \mathrm{L}$ NAA or media without growth regulator supplements, showed no differences in the number of shoots developing roots, however the roots from each treatment looked very different. Typically, those grown on hormone free media were long, and unbranched with only one root growing per shoot, whereas roots developing on NAA media were much shorter and thicker, with many root hairs, some secondary root branching and very often more than one root per shoot. As a consequence, the plantlets from the latter group were bushier and more robust (Fig. 3a), with approximately 80 \& surviving acclimatization and transplantation. Shoots that did not produce roots were left for subsequent testing.

\subsection{Selection III}

As expected, regenerated whole plants which survived in vitro selection I and II on selection media (C) had the highest survival rates after Harmony foliar spray treatment. All of these variant selections originated from callus from $2.5 \times 10^{6}$ M Harmony selection medium (passage 6; Table 4.3.)

Leo, wild type from seed (A) and regenerated control plants from in vitro selection $I$ and II (B) had a similar survival rate, 13.3 and 14.3 percent, respectively. These results may indicate that the inherent resistance found in the Leo population is constant and stable through tissue culture and 
regeneration procedures, and that the selection pressure exerted by the herbicide is a necessary selection factor, or is acting as a mutagen and is responsible for the resistance developed in the variant selections. This supports results reported by Brettel et al., (1980) and Larkin and Scowcroft (1983) where the recovery of resistant material was greater when the toxin was used than when it was dependent only on somaclonal variation (Duncan and Widholm, 1986). 
Table 4.2 Survival after selection II - SHOOT level

Harmony

In vitro

Percent

callus origin

N survived $\mathbf{N}$ tested

survival*

Control

4

33

12.1

Classic

9

59

15.3

Harmony

48

124

38.7

Classic

Control

Classic

Harmony
6

34

64
28

94

154
21.4

36.2

41.6

* Regenerated shoots selected in vitro on selection media supplemented with $10^{-6}$ M Harmony or Classic. 
Table 4.3 Survival after selection III - Whole plant level

\begin{tabular}{|c|c|c|c|}
\hline \multicolumn{4}{|c|}{ Harmony } \\
\hline Shoot origin & N survival & $\mathbf{N}$ tested & q survival \\
\hline $\begin{array}{l}\text { (A) Leo, control } \\
\text { from seed }\end{array}$ & 4 & 30 & 13.3 \\
\hline $\begin{array}{l}\text { (B) Control from } \\
\text { selection II }\end{array}$ & 5 & 35 & 14.3 \\
\hline $\begin{array}{l}\text { (C) Treated from } \\
\text { selection II }\end{array}$ & 9 & 25 & 36.0 \\
\hline Total & 18 & 90 & 21.6 \\
\hline & & assic & \\
\hline $\begin{array}{l}\text { (A) Leo, control } \\
\text { from seed }\end{array}$ & 3 & 30 & 10.0 \\
\hline $\begin{array}{l}\text { (B) Control from } \\
\text { selection II }\end{array}$ & 8 & 35 & 22.9 \\
\hline $\begin{array}{l}\text { (C) Treated from } \\
\text { selection II }\end{array}$ & 22 & 70 & 31.4 \\
\hline Total & 33 & 135 & 24.4 \\
\hline
\end{tabular}


4.2. Evaluation of Resistant Lines at the Cell Level - Callus from Regenerated plants

Harmony like other sulfonylurea (SU) herbicides functions by inhibiting the acetolactate synthase (ALS) enzyme, which catalyses the first step in the biosynthesis of the branchedchain amino acids necessary for such primary functions as cell division. Therefore, cell growth of selected lines can demonstrate whether the resistant trait is stable, i.e. still present at the cell level after regeneration.

Meristematic tips of regenerated plants were recultured to test this hypothesis. Callus of most of the selected cell lines was very slow to grow, while for several others, callus establishment was not evident, with explants becoming necrotic, after several weeks on B5M media (Fig. 4a). This indicates the occurrence of genetic or epigenetic changes not only attributable to the variant phenotype but also to additional pleiotropic changes. After six months of callus growth, enough material was accumulated from six of the twelve lines to perform the experiment described in section 3.3.A.

Results show that resistance at the cell level had been retained approximately 18 months after the initial selection and through regeneration for lines $\mathrm{H} 1-1, \mathrm{H5}-1, \mathrm{H} 5-7$ and $\mathrm{H5}-10$ (Table 4.4; Fig. 4b,c; Fig. 5). One line 5-7 which was not included in the field trials because cuttings were slow to grow was very resistant at the cell level. Interaction of main effects of cell lines and herbicide treatment was significant after four weeks 
Fig. 4a. (top) Callus initiation of Leo (left) and two regenerant lines after 20 days growth on MS medium supplemented with $2.0 \mathrm{mg} / \mathrm{L} 2,4-\mathrm{D}$.

4b. (middle) Callus of Leo and five resistant lines after two weeks growth on Harmony selection medium $\left(10^{-5} \mathrm{M}\right)$.

4c. (bottom) Callus of Leo and resistant line 5-1 after two weeks growth on $0.0,10^{-5}$ and $10^{-4} \mathrm{M}$ Harmony selection media. 
1
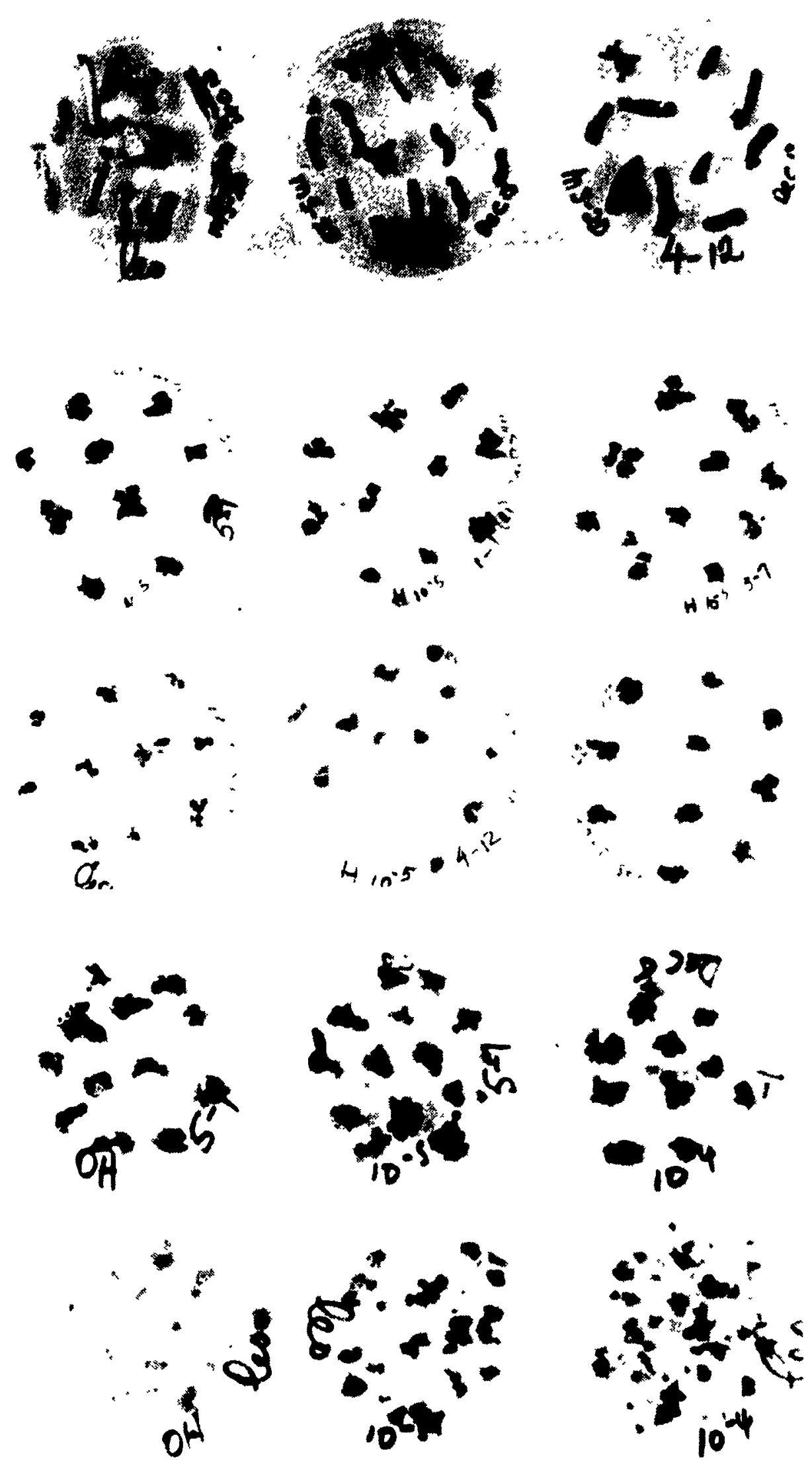
Table 4.4 Effect of Harmony selection mediun $\left(10^{-5} \mathrm{M}\right)$ on callus growth of regenerant lines after 2 and weeks

\begin{tabular}{|c|c|c|c|c|c|c|}
\hline \multirow[b]{3}{*}{ Cell Line } & \multicolumn{3}{|c|}{2 Weeks } & \multicolumn{3}{|c|}{4 Weeks } \\
\hline & \multicolumn{6}{|c|}{ Treatment } \\
\hline & C & $T$ & t of C & $c$ & $\mathbf{T}$ & $\&$ of $\mathrm{C}$ \\
\hline (A) LEO & 0.870 & 0.619 & 71.1 & 1.564 & $0.647^{* *}$ & 41.4 \\
\hline (B) $5-14$ & 1.054 & 0.724 & 68.6 & 2.563 & $0.796^{* *}$ & 31.0 \\
\hline (C) 1-1 & 0.784 & 0.728 & 93.0 & 1.656 & $1.209^{*}$ & 73.0 \\
\hline (C) 5-1 & 0.818 & 0.769 & 94.0 & 1.949 & $1.703 \mathrm{~ns}$ & 87.3 \\
\hline (C) $5-7$ & 1.138 & 0.989 & 86.9 & 2.246 & $1.940 \mathrm{~ns}$ & 86.4 \\
\hline (C) $5-10$ & 0.873 & 0.778 & 89.0 & 1.894 & $1.461^{*}$ & 77.1 \\
\hline
\end{tabular}

Treatments: $C=$ control, $O$ herbicide; $T=10^{-5}$ M Harmony selection media; of $\mathrm{C}=\mathrm{FW}(\mathrm{g})$ of $\mathrm{T}$ as a percent of respective control.

**, , significant at the 0.01 and 0.05 level respectively, using orthogonal contrast analysis.

ns, not significant at the 0.05 level. 


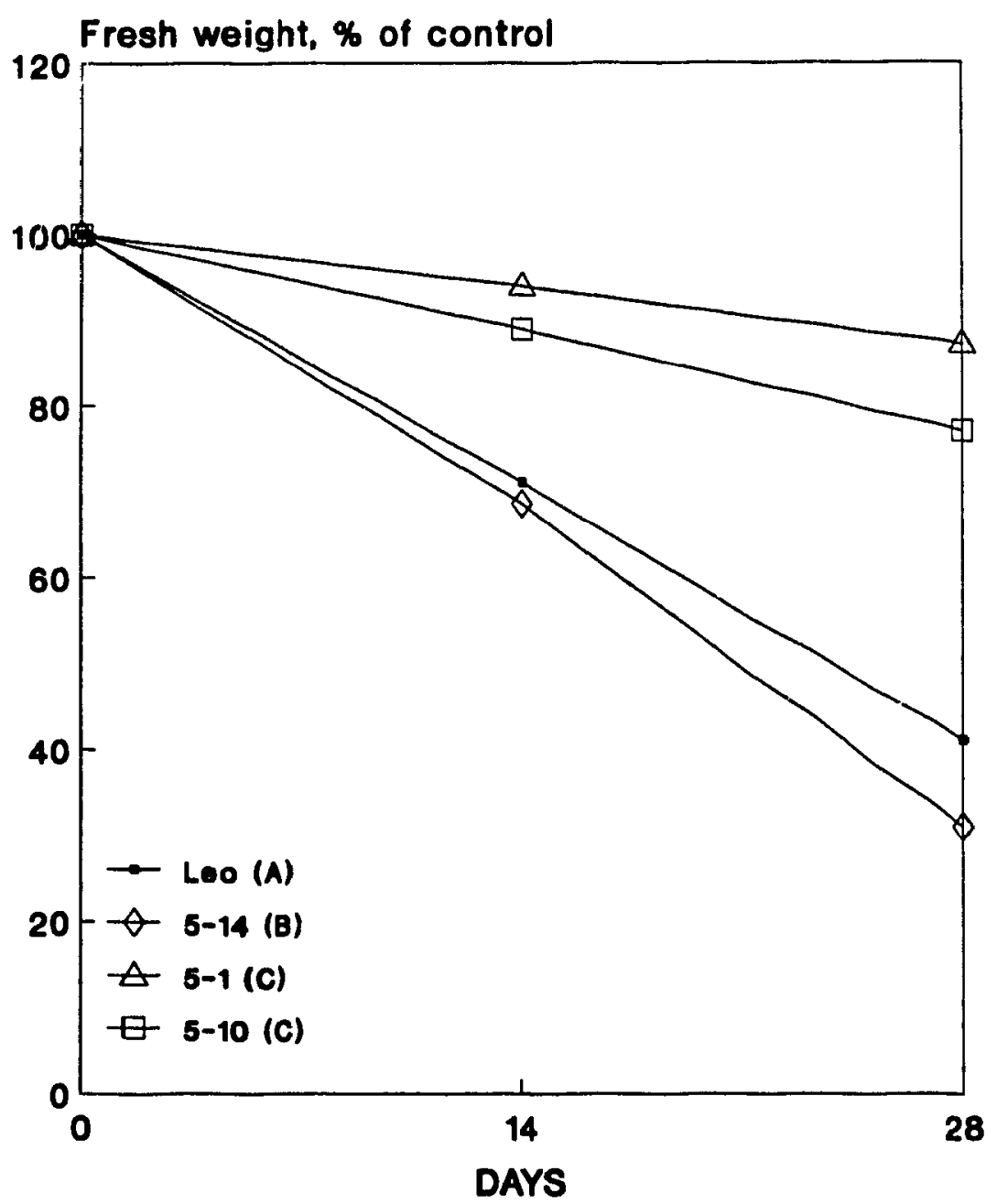

Fig. 5. Effect of Harmony $\left(10^{-5} \mathrm{M}\right.$ ) on callus growth (as a percentage of respective controls - 0 herbicide) of regenerant lines: (A) control from seed; (B) regenerant control from tissue culture; (C) regenerant selected resistant lines from tissue culture, after 14 and 28 days in vitro growth on selection medium . 
of callus growth using ANOVA procedure (Appendix 4).

Thus, orthogonal contrasts of simple effects comparing the control vs. herbicide treatments within genotypes were employed. Such contrasts show that the herbicide had a highly significant effect $(p<0.0001)$ on Leo controls, (A) and line 5-14 (B) whereas effects on selected lines 5-1 (C) and 5-7 (C) were not significant, signifying that tolerance has been retained for these lines.

\subsection{EVALUATION Of RESISTANT LINES at the WHOLE PLANT LEVEL}

\subsection{A. Growth Chamber and Field Data Analyses}

\subsection{A.i. Phytotoxicity:}

Injury caused by post-emergent spraying was first expressed in the unselected controls as severely stunted growth, followed by leaf chlorosis and meristem necrosis, whereas 2 n selected lines, some stunting and only slight yellowing of the leaf meristems were observed. These results demonstrate that the resistant trait selected for at the cellular level was also expressed by the whole plant. In addition to these initial symptoms, after approximately six weeks in the growth chamber, the selected variants (C) recovered, whereas the other selections, controls (A) and (B), lost most of their leaves and were extremely stunted (Table 4.5; Appendix 5).

The field dat for 1989, however is less conclusive in that a large percentage of the plants, including Leo controls from 
TABLE 4.5 Indoor study: Effect on height prior to (Week 0 ) and 6 weeks aftar herbicide application to cuttings of selected regenerant lines

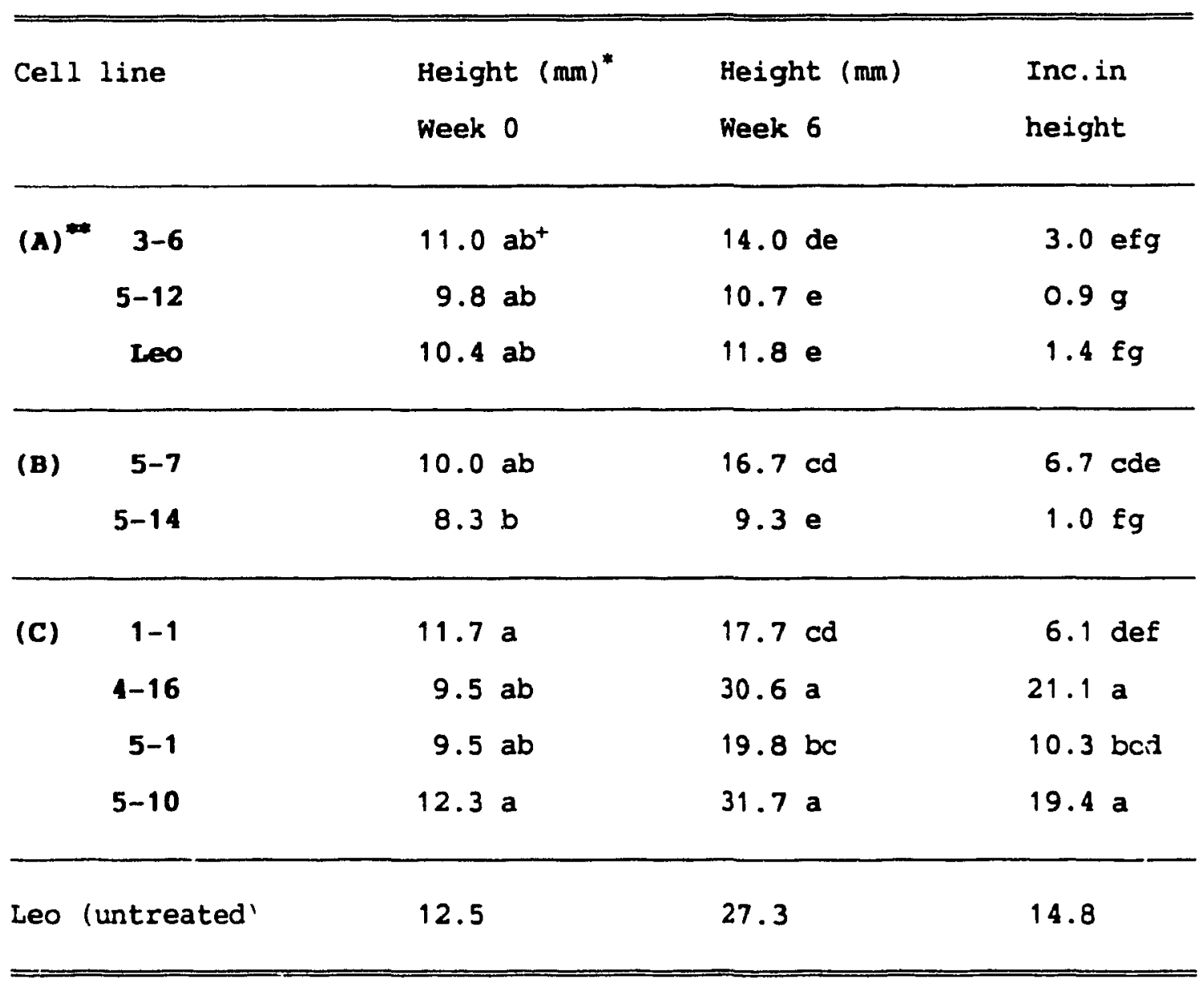

* Mean height is based on the average of three replications of each cell line at each treatment. Harmony application rate: $43.76 \mathrm{~g}$ ai/ha.

** (A) control plants from seed; (B) control plants from tissue culture; (C) selected variants from tissue culture.

+ Means followed by the same letter, within columns only, are not significantly different at the 0.05 level according to Duncan's Multiple Range Test. 
seed (A), recovered and grew vigorous new tillers following an initial period (4-5 weeks) of severe phytotoxic damage (Fig.7a, b). Similar results for field tested, transformed su tobacco plants were reported (Knowlton et al., 1988). They observed that with time, non-transformed plants began to recover and new growth was initiated. However, as described in the next section, a significant yield drop in controls occurred as a result of the herbicide application.

Harmony selections $\mathrm{H} 2-14, \mathrm{H} 2-12, \mathrm{H} 4-16, \mathrm{H} 5-1, \mathrm{H} 5-10$ had the lowest injury ratings in both growth chamber and field experiments. No consistency was found with the classic lines, and therefire, further evaluation was concentrated on Harmony selections. (At the same time, we were informed that classic was no longer being manufactured or distributed by Du Pont.)

Field data collected during the summer of 1990 are more conclusive. Phytotoxicity data were taken using the ranking scale described in section 3.2.C. The simple effects of cell lines at each herbicide level were analyzed separately using Friedmans two-way ANOVA by rank and followed by a multiple comparison test appropriate for this procedure (Table 4.6). Leo controls did not survive herbicide treatment at 30 and $60 \mathrm{~g}$ ai/ha. On the other hand, resistant selections 1-1, 5-1, and 510, survived foliar treatment of $100 \mathrm{~g} \mathrm{ai} / \mathrm{ha}$, approximately four times the recommended field rate. The different response observed in 1989 and 1990 may have been caused by the very hot 
Fig. 6a. (top) Flats of cuttings of selected variants, prior to planting, for field trial, (1989).

6b. (bottom)

Line H4-10 (bottom, left) and Leo (top, right) after three months growth in the field, (1989). 

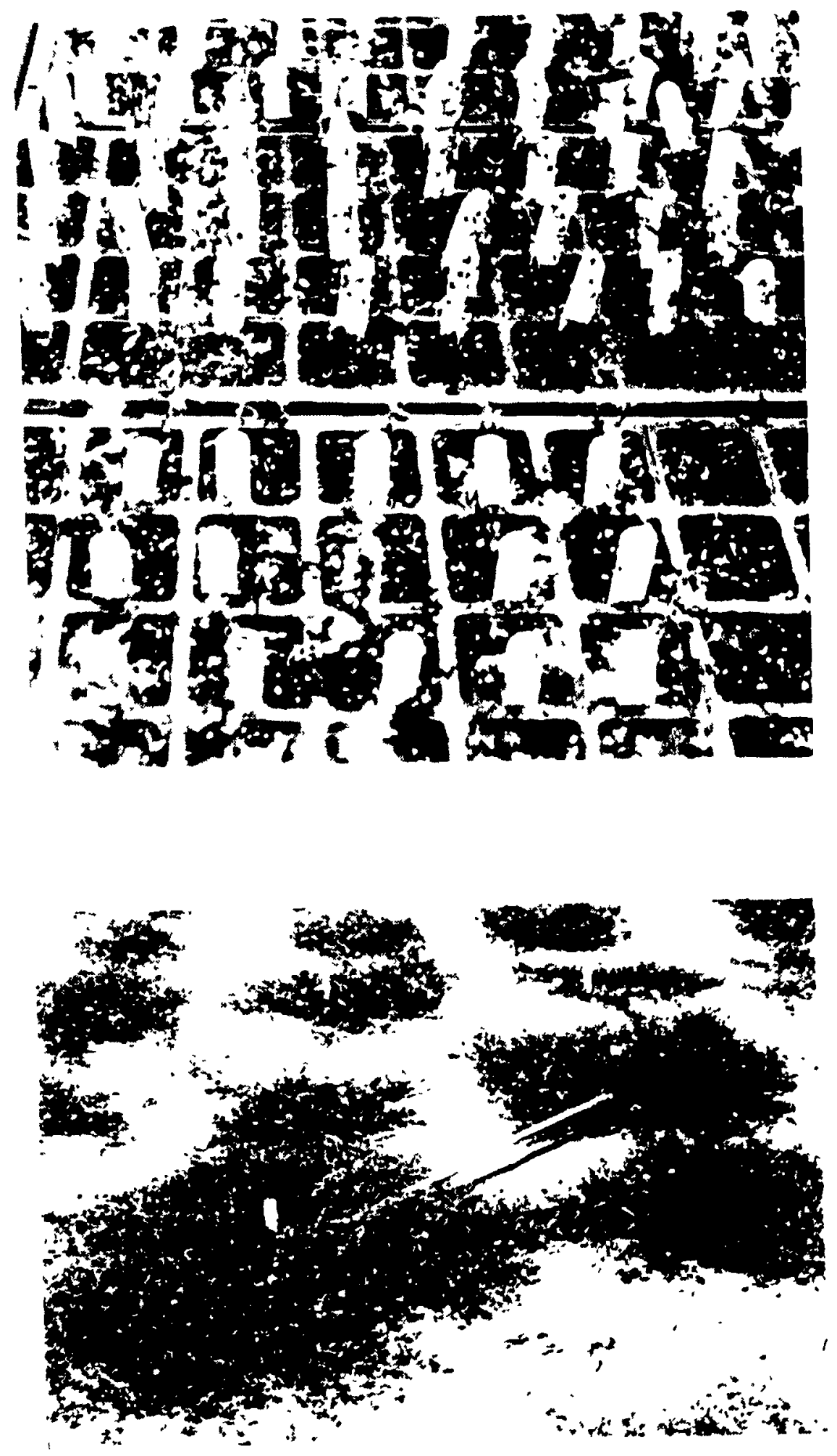
Fig. 7 .

Leo (top) and resistant selection $\mathrm{H} 4-16$ (bottom)

two weeks after Harmony application (43.76

$9 \mathrm{ai} / \mathrm{ha}$ ) from field trial (1989). 

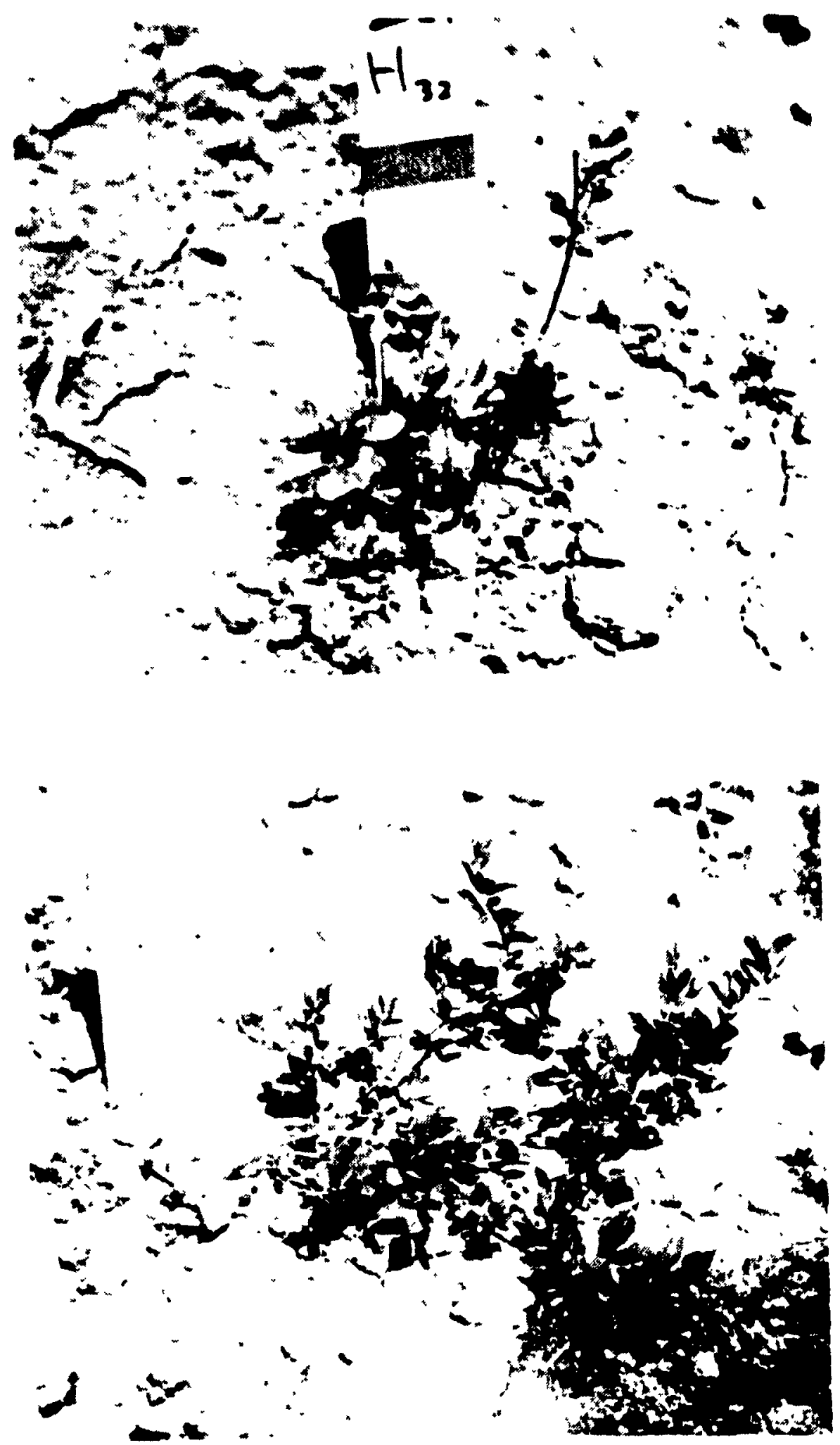
Table 4.6

LSD for mitiple comparisons on man injury rating of simple effects of genotypes at each herbicide level (Hi-H3). - from field trial 1990

\begin{tabular}{|c|c|c|c|c|c|c|}
\hline & & H1 & & $\mathrm{H} 2$ & & $\mathrm{H3}$ \\
\hline Cell & Mean & Actual & Mean & Actual & Mean & Actual \\
\hline line & rank & rating & rank & rating & rank & rating \\
\hline (A) $\mathrm{LeO}$ & $1.0 \mathrm{a}$ & $(3.18)^{+}$ & $1.0 \mathrm{a}$ & $(2.2)$ & $1.0 \mathrm{a}$ & $(2.54)$ \\
\hline (C) $1-1$ & $3.4 b$ & $(7.0)$ & $3.3 b$ & $(7.2)$ & 3.16 & $(6.36)$ \\
\hline (C) $5-1$ & $2.6 a b$ & $(6.6)$ & $2.8 \mathrm{~b}$ & $(7.4)$ & $2.7 a b$ & $(5.64)$ \\
\hline (C) 5-10 & 3.06 & $(6.52)$ & $2.9 b$ & $(6.36)$ & $3.2 b$ & $(5.68)$ \\
\hline Chi-squared & $9.96^{*}$ & & $9.42^{*}$ & & $9.42^{*}$ & \\
\hline TSS & 16.6 & & 15.7 & & 15.7 & \\
\hline
\end{tabular}

LSO for multiple comparisons $=9.14$. Mean ranks followed by different letters, in the same column only, are significantly different at the 0.15 experiment wise error rate.

$H-1, H-2, H-3=30,60,1009$ al/ha Harmony, respectively.

+ values in parantheses are the means of 5 replications of 9 combined ratings over a 3 week period that followed herbicide application.

* chi-squared values significant at the 0.05 leve1. 


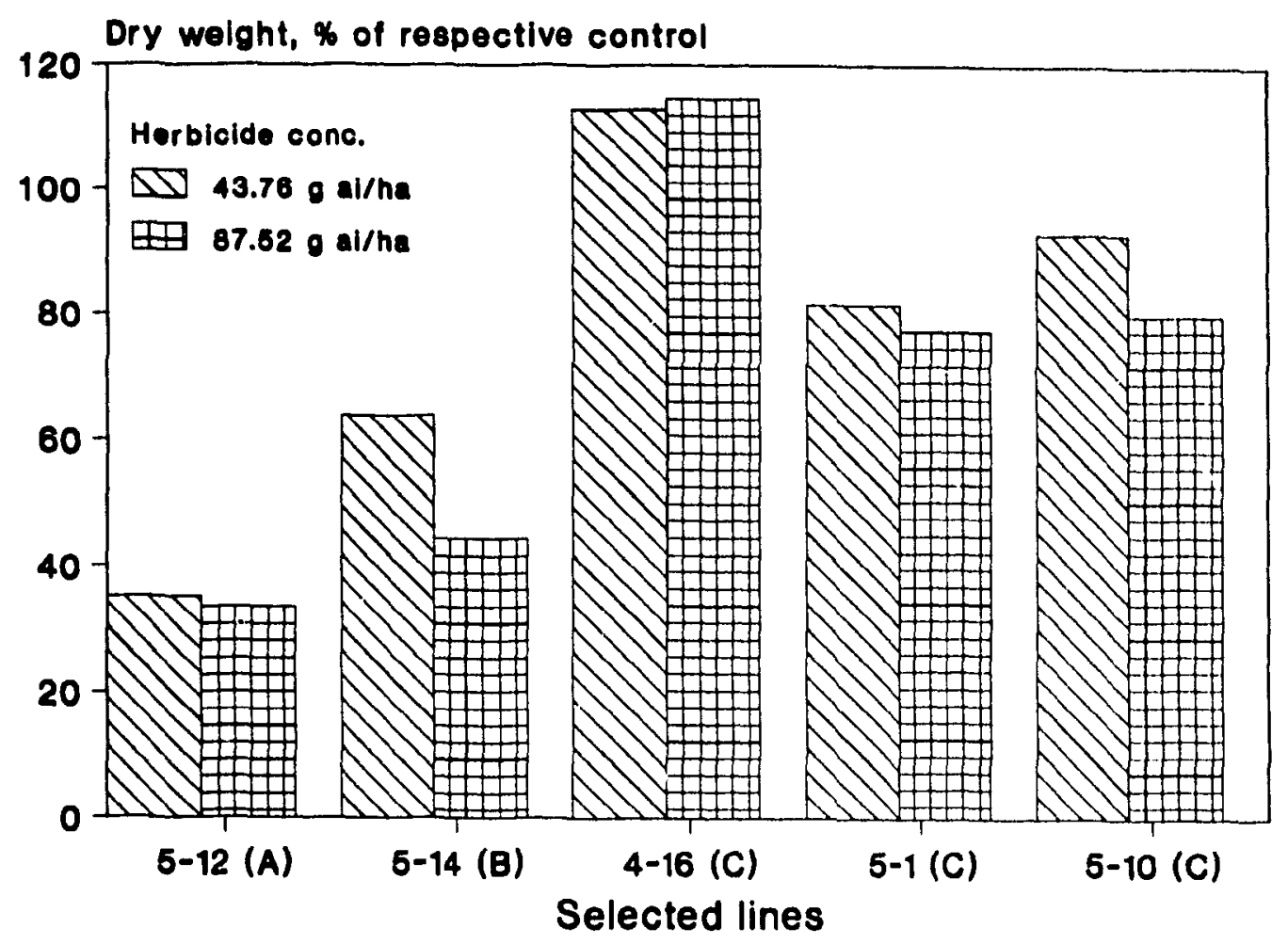

Fig.8. Dry weight forage yield, as a percentage of respective controls, in response to a foliar application of Harmony (DPX6316) to (A) control plants from seeds; (B) control plants from tissue culture; (C) selected resistant lines from tissue culture. 
and dry period in May 1990. The reaction of wild type plants to the herbicide, in combination with the drought stress, may have been too much to surpass, and consequently most of these control plants died. Grant and Marten (1985) and Madill et al., (1980) noted that herbicides can suppress growth of trefoil and cause serious crop damage under conditions of drought or high temperature. Blair and Martin (1988) discuss the fact that high temperatures enhance the effects of CS and metsulfuron activity in sensitive species like sinapus alba L., while this is reversed with tolexant species such as wheat. They surmise that this may be a reflection of an increased metabolic rate of the herbicide in the tolerant species. Results from field-grown in vitro selected plants demonstrate that there is a gradient of tolerance in trefoil and mutant selections and the field trial emphasizes the importance of testing these plants under varying conditions of agronomic practice.

\subsection{A.i. Yield:}

Dry weight yield was measured after three months growth in the field (1989), and it is evident that herbicide application affected overall forage yield. It can be summarized from Fig. 8, tinat dry weight of selected variants (C) was less affected by the herbicide application, than wild type from seed (A) or control regenerants from culture (B). Dry weight forage yield was converted to a percentage of respective control means (untreated) to adjust for inherent yield differences between 
cell lines. Similarly, orthogonal contrasts of simple effects comparing herbicide levels within genotypes was used. These results show that the herbicide had a highly significant effect (p<0.0001) on wild type from seed (A), Leo and line 5-12, whereas most of the resistant selected lines displayed no significant herbicide effect (Appendix 6A).

\subsection{A.iii. Flowering and Fertility:}

As expected, several of the selections were sterile. Five lines, $\mathrm{H} 1-10, \mathrm{H} 2-14, \mathrm{H} 4-12, \mathrm{H4}-16$, and $\mathrm{H4}-17$, produced flowers but pod and seed formation were aborted. Also, these variants appeared to be less fit than the wild type. Gressel et al. (1978) have attributed this problem to tissue culture techniques, and somaclonal variation causing multiple mutations, many of which are deleterious. In general, this has been a major problem with cell culture derived herbicide resistant plants.

However, three lines, $\mathrm{H} 1-1, \mathrm{H} 5-1$ and $\mathrm{H} 5-10$, with increased herbicide tolerance levels are fertile. Morphologically these plants are very similar to Leo for most quantitative traits measured (Table 4.7).

Pollen stainability tests of all lines tested do not support fertility findings, as percent viable pollen was not significantly different in any of the selections.

Flowering (1989) was delayed by herbicjde application to Leo, control plants (A) and control regenerants (B), but not to the putative mutant selections (C) (Appendix 6B). In a similar 
experiment, Swanson et al., (1988) noted that maturity was delayed in Brassica napus regenerants when $6 \mathrm{~g} / \mathrm{ha}$ CS were incorporated in the soil. Jordan and McHughen (1987) reported comparable results with flax regenerated from CS resistant selected callus. Delay in flowering to a period of less than optimal conditions can lead to seed yield reductions and insect/seed problems in trefoil (personal communication with P.R. Beuselinck)

\subsection{B Plant Line H4-10}

Plants of a regenerant line H4-10, (Fig. 6b), derived from the herbicide selection regime, had a significantly higher forage yield than the current cultivar, Leo, in the 1989 field trial. To determine whether this phenotype was genetic, outcrossed seeds, collected from the above trial (1989), were tested the following summer $(1990)$. The results from the 1990 variety trial demonstrate that these plants were larger in diameter and had a higher total dry weight yield than Leo. One plant (401-4-1a) after harvesting had a dry weight of 284 grams. The average dry weight of 40 Leo plants was 131,70 grams vs. 175.30 grams for the average of line 4-10. In line 4-10, 14 plants out of the 40 weighed over 200 grams vs. five plants for Leo.

Other measurements taken at the same time to establish whether these increases in yield and diameter were associated with any other phenotypic traits (described in 3.3.C.ii) were 
Table 4.7 Variety Trial 1990

\begin{tabular}{|c|c|c|c|c|}
\hline \multicolumn{5}{|c|}{ Cell Line } \\
\hline Parameter & $4-10$ & Leo & $5-1$ & $5-10$ \\
\hline Yield & $175.30 \mathrm{a}^{* *}$ & $131.70 \mathrm{~b}$ & $138.97 b$ & $130.70 b$ \\
\hline Height & $13.28 b$ & $16.98 a$ & $10.46 c$ & $10.84 c$ \\
\hline CLL & $2.10 a$ & $2.04 a$ & $1.84 b$ & $1.98 a b$ \\
\hline CLW & $0.80 b$ & $0.94 a$ & $0.75 b$ & $0.84 a b$ \\
\hline FBL & $1.22 \mathrm{ab}$ & $1.20 \mathrm{ab}$ & $1.11 \mathrm{~b}$ & $1.26 a$ \\
\hline FBW & $0.32 a$ & $0.33 a$ & $0.31 \mathrm{a}$ & $0.33 a$ \\
\hline IL & $2.93 a$ & $2.57 b$ & $2.61 \mathrm{ab}$ & $2.63 \mathrm{ab}$ \\
\hline $\mathrm{FL}$ & $1.23 a$ & $1.19 a$ & $1.19 a$ & $1.22 a$ \\
\hline $\mathrm{OL}$ & $0.62 a$ & $0.60 a$ & $0.60 \mathrm{a}$ & $0.61 a$ \\
\hline
\end{tabular}

*YIELD(g); Height (cm);CLL/CLW=central leaf length/wodth (cm); FBL/FBW=floral bract length/width $(\mathrm{cm}) ; \mathrm{IL} / \mathrm{FL} / \mathrm{OL}=1$ nternode/flower/ovary length $(\mathrm{cm})$.

**Means followed by the same letter. within a row only, are not significantly different at the 0.05 probability level according to LSD test 
analyzed with the general linear model analysis for a randomized complete block design, followed by the LSD test (Table 4.7) The quantitative parameters that were found to be significant for 410 were yield, height, central leaflet width and internode length.

\subsection{In Vitro Seed Germination Tests}

From Table 4.8 it may be concluded that the herbicide resistant trait is heritable (Fig. 9a,b,c). Germination of seeds with the resistant phenotype was considerably lower than for wild type seeds. The reasons for this are not immediately evident, but a lower fertility rate, an increased susceptibility to insect or microorganismal damage, or a shortened shelf life are some possibilities.

Since Lotus corniculatus is an outcrossing, autotetraploid species and the seeds used for this test were from outcrossed plants collected from the field experiment describel in section 3.3.B, it is difficult to surmise inheritance patterns without a controlled genetic analysis study. Crosses using the fertile selections from the field were attempted in the greenhouse and the growth chamber but enough seed was not produced from any of the selections to do a conclusive study. The lack of proper crosses has thus prevented further genetic analysis of these herbicide resistant variants. 
Fig. 9a. (top) Seeds of (clockwise) Leo and resistant lines 1-1, 5-10, and 5-1 germinating on Harmony $10^{-5} \mathrm{M}$ selection media. After three weeks of growth secondary leaf formation is visible on resistant lines but not on Leo (bottom, left)

9b. (middle)

Close-up of line 5-1

9c. (bottom)

Comparison of root growth of a resistant line (left) and Leo (right) on Harmony selection media $\left(10^{-5} \mathrm{M}\right)$ after two weeks growth 

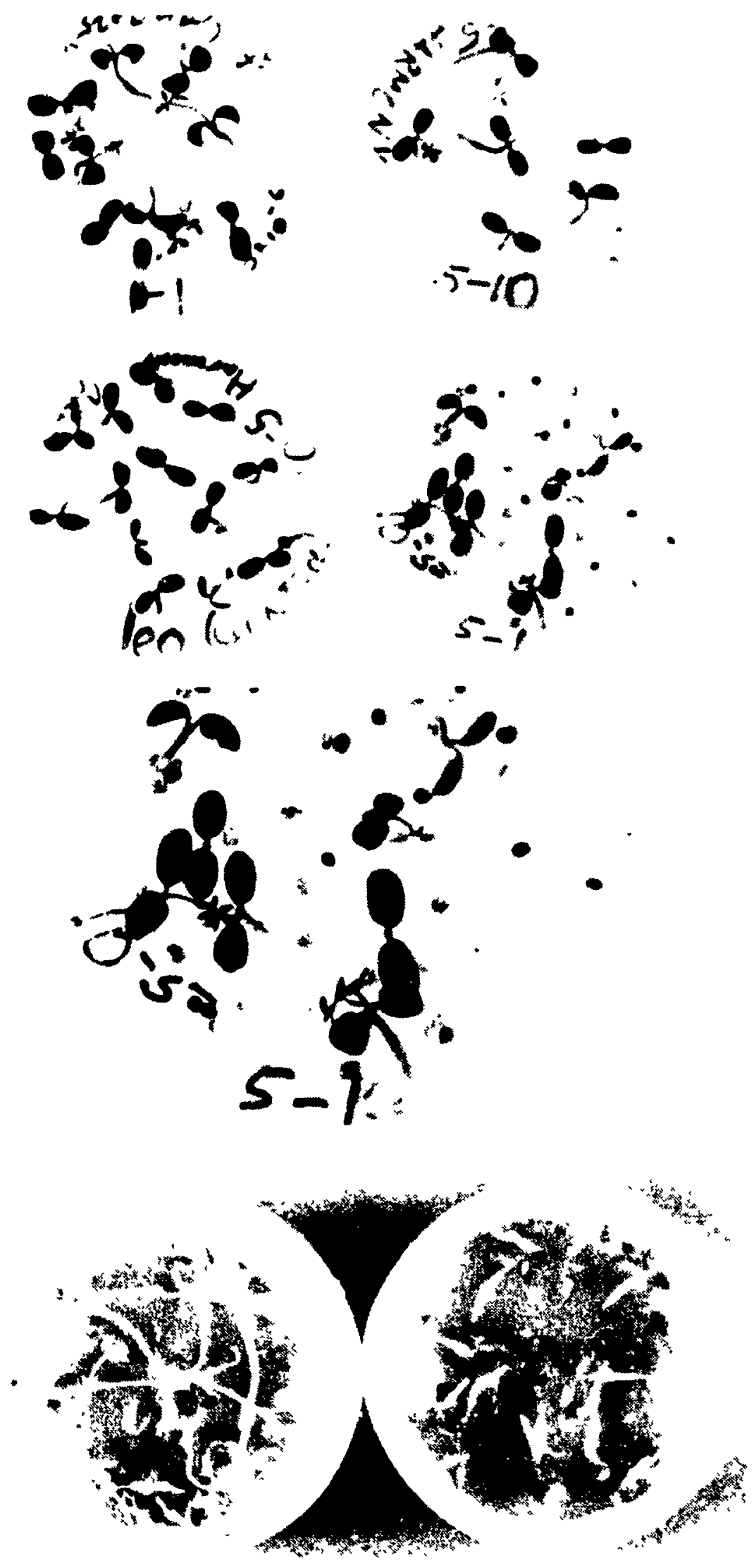
Table 4.8 Effect of herbicide on in vitro seed germination of resistant lines

Cell line

$\mathbf{N}$ tested

$\mathrm{N}$ resistant

\& resistant

(A)

Leo

164

3

1.8

$3-6$

78

1

0.6

5-12

118

1

0.9

(B) 5-14

54

1

1.9

(C) 1-1

137

56

40.9

4-10

160

3

1.9

5-1

101

36

35.6

5-10

74

26

35.1

*Seeds that germinated and grew secondary leaves on selection media with $10^{-5}$ M Harmony.

** (A) control lines from seed;

(B) control lines from tissue cultura;

(C) selected mutant lines from tissue culture. 


\subsection{CYTOGENETICS :}

The genetic variation in somatic cells of plants regenerated from culture, somaclonal variation, has been reported extensively and discussed in section 2.2 and 2.3 . It has been suggested that these changes are a response by the plant to an imposed stress and that this stress can increase the spontaneous mutation rate.

Cells in general have a tendency to besome polyploid, a response by the plant to a condition which may preexist in tissues that are mosaics of ploidies or induced directly during the culture process (Duncan and widholm, 1986). These ploidy alterations can result from endomitosis, endoreduplication, division of two nuclei on one spindle, multiple spindle forrution at anaphase, or chromosome bridge formation and chromosome breakage (Chaleff, i381; Larkin and Scowcroft, 1981; Orton, 1984 as sited in Duncan and Widholm, 1986). Furthermore gross chromosome alterations usually result in serious phenotypic abnormalities including a decrease in fertility or complete sterility, and can often be lethal because of the loss of many genes (Karp and Bright, 1985).

Due to the small size of trefoil chromosomes, it requires considerable time and expertise to determine the exact chromosome numbers of individuals. Chromosome counts, of the 12 Harmony selections show that of the five infertile selections, four are in the octoploid range $(2 \underline{n}=8 \underline{x}=48)$ and one $(H 4-12)$ is aneuploid with approximately 45 chromosomes (Fig. 10b). All 
the selections that flowered and produced seed had the normal complement of chromosomes $(2 \underline{\mathrm{n}}=24)$.

Other studies using in vitro selection of trefoil have also produced regenerants with gross phenotypic and genotypic abnormalities. In this laboratory, MacLean and Grant (1987), found that 20 percent of callus culture regenerants had aneuploid, mixoploid or polyploid chromosome numbers. Tomes (1982) reported similar results where 20 percent of the trefoil regenerants were polyploid, several of the 'normal' regenerants had reduced male fertility and seed set, and a number falled to flower.

Chromosome number changes also appear to involve other phenotypic changes. Large leaves, a dark green colour, reduced petiole length, thick internodes and large florets are characteristics associated with polyploids in general (BIngham and McCoy, 1986) and were evident in these selections as well (Fig. 12a,b,c). Polyploidy also was associated with stunted growth habit and, in general, lower dry-weight yield.

\subsection{ACETOLACTATE SYNTHASE ENZ YME ASSAY}

In order to determine whether a mutant ALS was the basis for Harmony resistance, it was found, after performing several replications of the assay, that ALS inhibition of mutant selections is somewhat lower than the Leo controls (Fig. 10 and 11). The results from the analysis of variance show non significant interaction between genotype and herbicide. Main 
Fig. 10a. (top)

ALS enzyme assay; Leo (left) and line 5-10 (right), herbicide concentration from left to right $0,1,10,100,1000 \mu \mathrm{g} / \mathrm{L}$ Harmony . (Inhibition of ALS is translated as less color development in this assay)

$10 . \mathrm{b}$ (bottom)

Chromosomes from line 4-12 showing polyploidy 

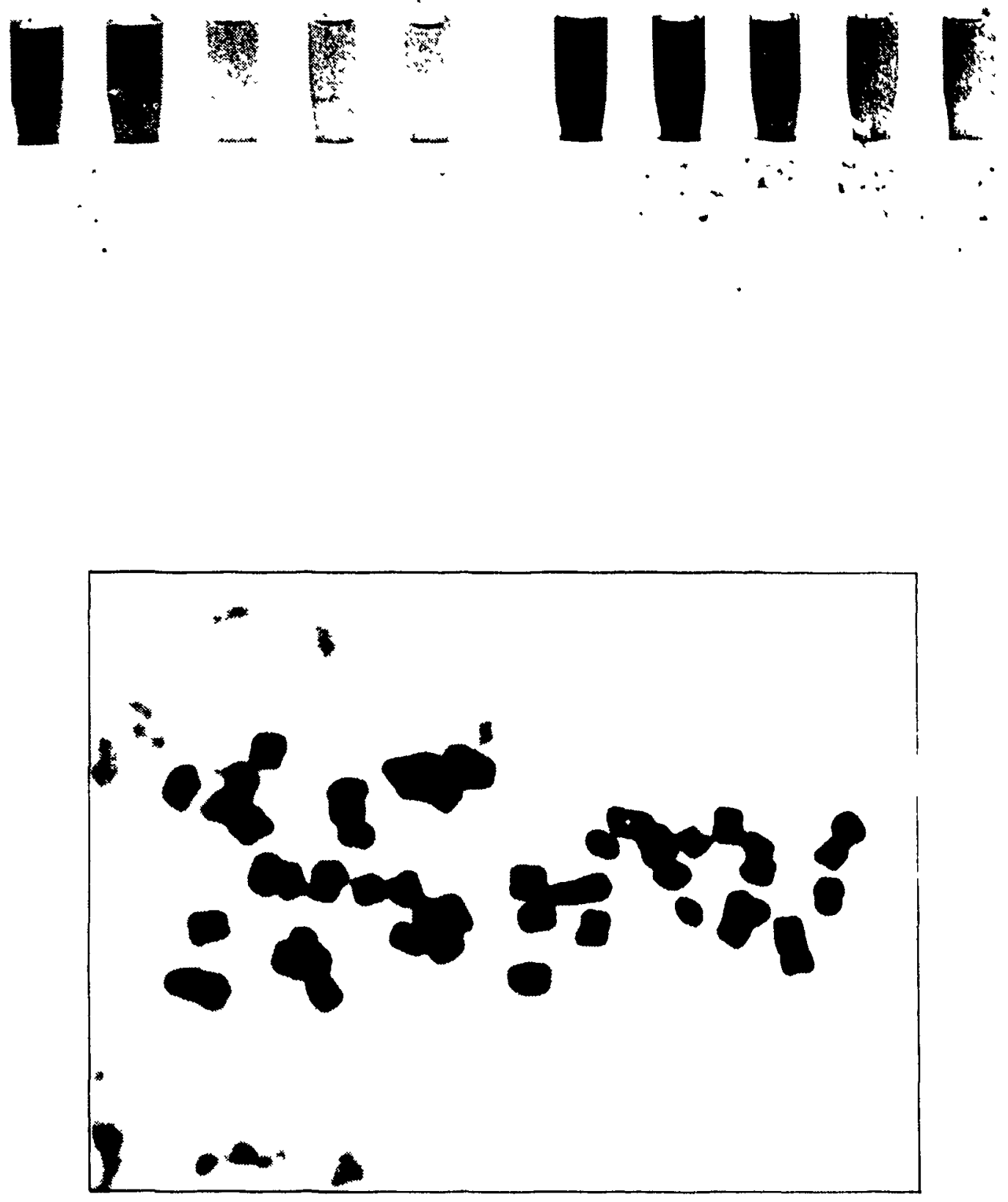

H4-16, of Stem section: Leo, left; 4-16, right Flower: Leo, left; 4-16, right Leaf: 4-16, left; Leo, right 

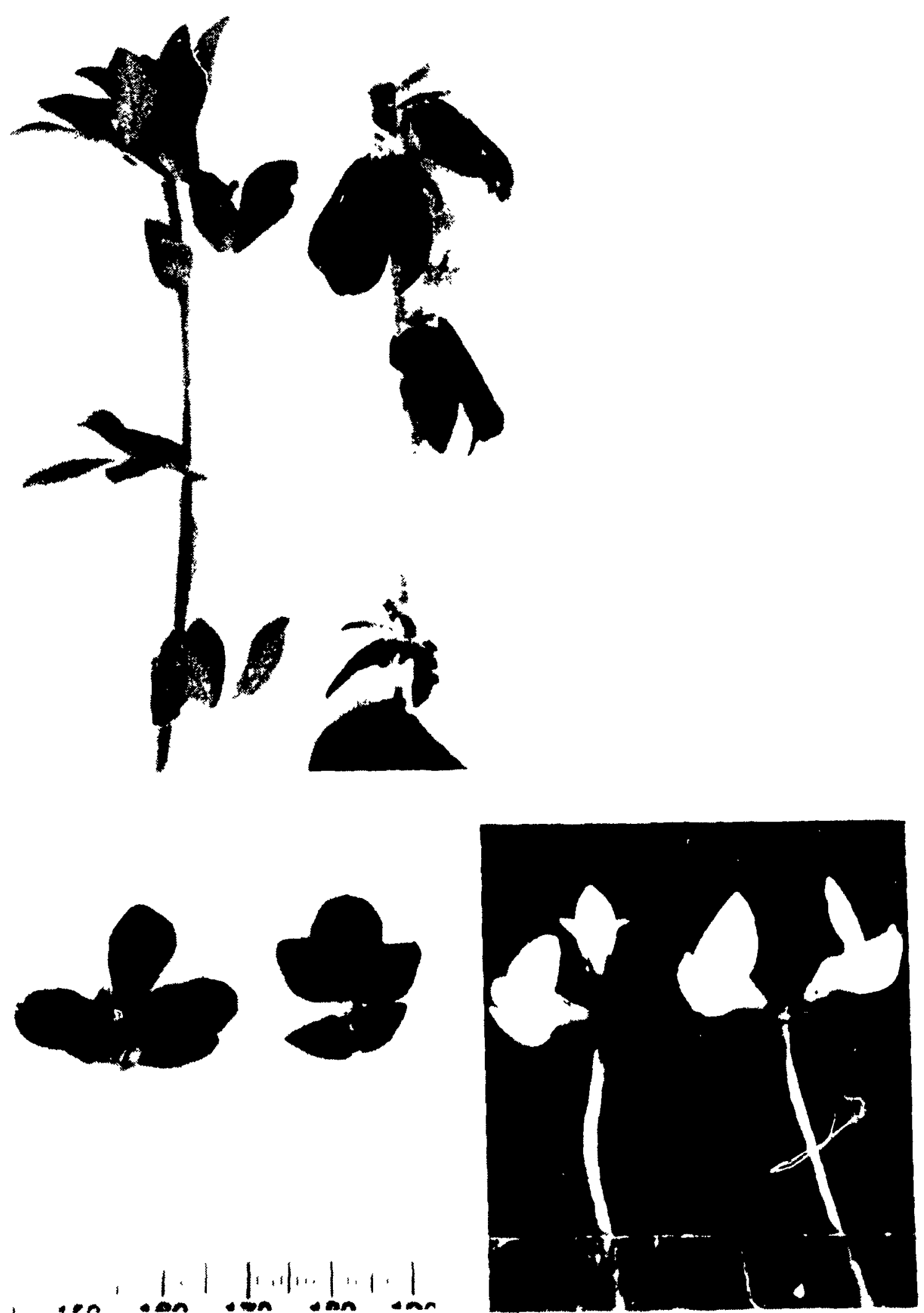


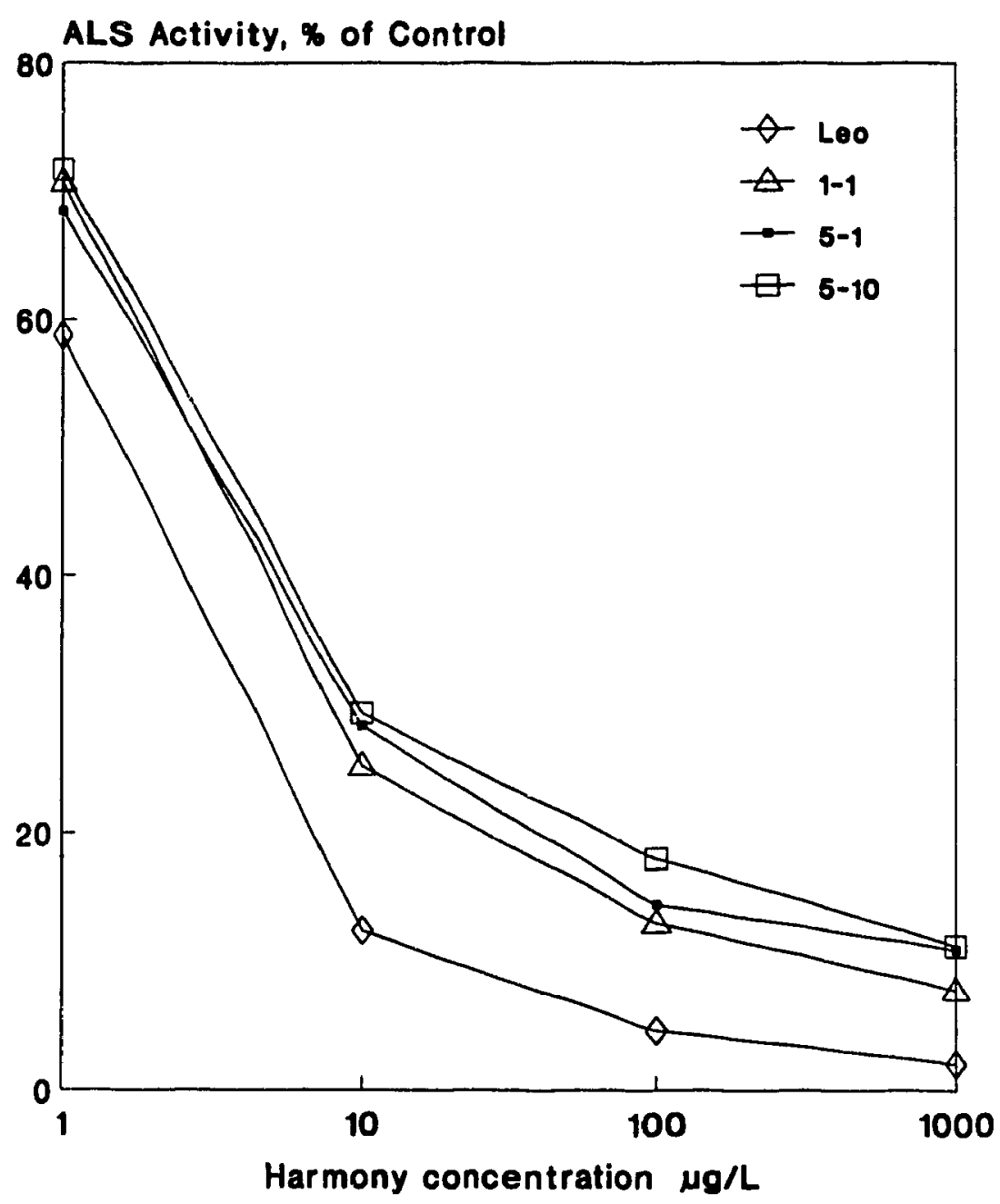

Fig. 11. Percentage of acetolactate synthase activity, (as a percent of respective controls) remaining in wild type (Leo) and mutant lines 1-1, 5-1, and 5-10 leaf extracts at increasing concentrations of Harmony. 
effects of genotype and herbicide were significant. Duncan's test for comparisons of means indicates that the Leo response to the herbicide is significantly different from all the other lines tested (Appendix 7).

It may be concluded that a mutant ALS gene with an altered binding site is responsible. This, however, is not certain, since most gene mutations associated with increased SU resistance cited in the literature describe ALS resistance levels of 10 to 1000 fold that of the wild type levels (Chaleff and Mauvais, 1984; Haughn and Somerville, 1986; Swanson et al., 1988 and Saxena and King, 1988). A CS resistant tobacco mutant isolated from cell culture had an $I_{50}$ value that was $>8000 \mathrm{nM}$ compared to $14 \mathrm{nM}$ for the wild type (Chaleff and Mauvais, 1984). The $I_{50}$ values for ALS inhibition for CS susceptible and resistant Kochia biotypes were 22 and $400 \mathrm{nM}$ respectively (Saari et al., 1990).

On the other hand, Sebastian et al., (1989) described the CS soybean mutant, w20, as resistant, which had a threefold greater enzyme activity than the wild type remaining at $200 \mu \mathrm{g} / \mathrm{L}$ CS. $I_{50}$ values were 10 and $24 \mathrm{ug} / \mathrm{L} \mathrm{CS}$ for sensitive and resistant soybean lines respectively. In our study, (Fig. 11), the percentage ALS activity remaining for lines $0-1$ and $5-10$, at the highest herbicide concentration tested, $1000 \mu \mathrm{g} / \mathrm{L}$, was two times greater than activity remaining in Leo. At $100 \mu \mathrm{g} / \mathrm{L}$, there was approximately a threefold increase in activity remaining for selection 5-10 as compared to Leo. $I_{50}$ values are 2.5 and 5.5 
$\mu \mathrm{g} / \mathrm{L}$ Harmony for Leo and line 5-10 respectively. A similarity does exist with the Sebastian study and it is interesting to note that both are selecting plants from the legume family. Alternatively, an amplified ALS gene may be responsible for the differential tolerance in selection 5-10 where the protein levels were found to be higher than the wild type. Total protein in enzyme extracts was $4.95 \pm 0.30 \mathrm{mg} / \mathrm{mL}$ for $5-10$ and $4.05 \pm 0.39$ $\mathrm{mg} / \mathrm{mL}$ for Leo. Meredith (1984) has suggested that a stepwise selection procedure, as used in this experiment, may favor the selection of genotypes resulting from gene amplification or mutations in organelle genomes. This phenomenon was also seen in bacteria and in cultured animal cells where specific genes can undergo amplification when the cells are placed under selective conditions (Stark and Wahl, 1984). 


\section{SUMMARY and CONCLUSION}

The resistant phenotype which was expressed in callus derived from regenerated lines, in seedlings and plants from outcrossed seeds, establishes that the resistance is expressed at all stages of development and is heritable. ALS enzyme assays indicate that at the bio -hemical level the resistant lines $H 1-1$, H5-1 and H5-10 are only somewhat more tolerant to Harmony than Leo, wild type. However, the field trial results demonstrate a high degree of resistance. Selected mutant lines were able to continue to grow and mature without any serious setbacks after herbicide treatment, whereas in wild type plants, severe morphological and physiological damage were seen to accumulate, affecting maturity, pod formation, and final yield. This normal development is important for herbicide resistant Lotus corniculatus crops which would be grown for forage and for seed.

Plants of line H4-10 may have cultivar potential, but it is not one of the lines that was resistant to herbicides. Also, the plants were somewhat more prostrate than desired in a cultivar. A breeding program using cultivars with an upright growth habit and SU resistance is an approach that should be further investigated. Research to identify any phenotypic and genotypic traits that may be correlated with increased yield should also be carried out.

As mentioned above, researchers working with SU herbicides have described ALS gene mutations conferring up to 1000-fold 
levels of resistance compared to the wild type. Thus, it cannot be concluded here that als is the biochemical mechanism responsible for the resistant phenotype of these trefoil selections until further studies are performed. One has to examine other mechanisms of herbicide resistance which can be achieved by the plant.

Some possibilities include gene amplification, the overproduction of an herbicide sensitive biochemical target, as described for tobacco resistant to glyphosate (Dyer et al. 1988) and for yeast and E.coli resistant to sulfometuron methyl (Falco and Dumas, 1985). Detoxification systems, the degradation of the herbicide to non-phytotoxic derivatives before it can reach the herbicide sensitive target, exist in many plant species. In metribuzin tolerant tomato plants, detoxification involves increased activity of the enzyme N-glucosyltransferase, and tolerance is controlled by one gene (Comai and Stalker, 1986). Cereal crops have considerable tolerance for CS which allows CS to be used selectively to control weeds (Falco and Dumas, 1985). similarly, it was found that resistance in several corn genotypes to Harmony was solely due to metabolism of the herbicide, and neither ALS sensitivity, nor differences in retention, absorption and translocation were responsible for the differential tolerance observed (Eberlein et al. 1989). It still remains to be defined in what way these selected variants have achieved herbicide resistance. If increased detoxification or physiological processes, such as reduced uptake, translocation 
or metabolism are involved, radioactive labelled stridies may elucidate this point and could be a topic for further study.

The different degrees of resistance displayed in this study, by the resistant variant cell lines $1-1$ and $5-1,5-10$ in callus and seed germination tests suggest that mutations may have arisen independently and that separate mutations may be found for trefoil aLs gene(s) that confer differential herbicide sensitivity. Investigating these plants at the molecular leved may answer some of these questions. Furthermore, seeds of selected lines selfed and backcrossed with leo would elucidate much of the needed information on the inheritance patterns, linkage groups and type of gene(s) involved, although genetic analysis with outbreeding polyploids is exceedingly complex.

The difficulty in establishing stands of trefoil has been shown to be alleviated by weed control (Wakefield and skaland, 1965), however trefoil is sensitive to herblcides at the seedling stage. In field experiments with applications of 30.0 $100.0 \mathrm{~g}$ ai/ha Harmony, selected variants (at the three trifoliate stage) were not only able to survive but showed only a marginal decrease in yield as compared to their respective untreated controls. Leo, on the other hand, was severely damaged and many of the samples tested did not survive. Despite the drop in overall yield of the tissue culture selections these lines can be useful in heavily weed infested fields where the increased safety margin between crop and weed sensitivity is important. They can also he used in fields with sulfonylurea 
residues making crop rotations more flexible. Alternatively their use in conventional breeding programs with trefoll or other corniculatus species for improved su resistance or as an identifiable marker in future scientific research with Lotus corniculatus is important. Also on the plus side, is the fact that Harmony is an herbicide that is highly effective, safe and rapidly biodegraded with low soil residues, and obtalning a tolerant crop species would minimize potential damage to the environment.

On the other hand, serious weed infestations is one of the problems expected from engineered plants in general and these regenerants in particular since tolerance of the wild type to the SU herbicides at low levels is somewhat inherent. (ALS assay, Field test 1989). Furthermore, since Lotus is an outcrossing species, possible exchange with wild relatives can also be detrimental from an evolutionary perspective where the development of weeds from the crop itself is not unlikely. Since trefoil is a cultivar with high inherent weediness and with weedy relatives as well, it will require continuous monitoring and siringent pesticide management practices to avoid problems of establishment.

The importance of producing herbicide resistant plant cultivars is evident, but it is equally evident that the task cannot be easily accomplished. Cell culture techniques are,a valuable tool for plant improvement and have met with some success but have disadvantages one of which is that the 
mechanism of resistance may often be unknown.

To attain more consistent rusults a better understanding of the basic physiological and genetic mechanisms underlying somaclonal variation must be achieved. Moreover in the long run to efficiently produce a herbicide resistant cultivar it may be necessary to look to different areas of biotechnology, such as introducing tolerance into a crop species by gene transfer methodology. At the present time the ALS gene from CS resistant plants is available along with transformation vectors and procedures for Lotus transformation (Webb, 1986; Petit et al. 1987). However, in theory this looks like a straight forward research project whereas in practice a whole new set of problems may have to be overcome. 


\section{BIBLIOGRAPHY}

Armstrong, K.C., Nakamura, C. and W.A. Keller. 1983. Karyotype instability in tissue-culture regenerants of triticale ( $\mathrm{x}$ Triticosecale Wittmack) cv. Welsh from 6-month-old callus

cultures. $Z$. Pflanzeng. 91:233-245

Armstrong, C.L. and R.L. Phililips. 1988. Genetic and cytogenetic variation in plants regenerated from organogenic and friable, embryogenic tissue cultures of maize. Crop Sci $28: 363-369$.

Bayliss, M.W. 1980. Chromosomal variation in plant tissues in culture. Int. Rev. Cytol. (Suppl.) 11A: 113-139.

Bebeli, P., A. Karp and P.J. Kaltsikes. 1988. Plant regeneration and somaclonal variation from cultured immature embryos of sister lines of rye and triticale differing in their content of heterochromatin 1. Morphogenetic response. Theor. Appl. Genet. 75:929-936

Beyer E.M., H.M. Brown and M.J. Duffy. 1987. SuJ.fonylurea herbicide soil relations. In Br. Crop prot. Conf. Weeds, $2: 531-540$.

Bingham, E.T. and T.J. MCCoy. 1986. Somaclonal variation in alfalfa. Plant Breed. Rev, 4:123-152,

Blair, A.M. and T.D. Martin. 1988. A review of the activity, fate and mode of action of sulfonylurea herbicides. Pestic. Sci. 22:195-219.

Brettel, R.D., S. Ingram and S. Thomas. 1980. Selection of maize tissue cultures resistant to Drechslera (Helminthosporlum maydis) T-Toxin. In Tissue culture methods for plant pathologists. D.S. Ingram and J.P. Helgelson eds. Blackwel1, London. pp. 233-237.

Chaleff, R.S. 1981. Genetics of higher plants: applications of cell culture. Cambridge Univ. Press, Cambridge.

Chaleff, R.S. 1983. Isolation of agronomically useful mutants from plant cell cultures. Science, 219:676-682.

Chaleff, R.S. and M.F. Parsons. 1978. Direct selection in vitro for herbicide-resistant mutants of Nicotiana tobaccum. Proc. Natl. Acad. USA. 75:5104-5107.

Chaleff, R.S. and C.J. Mauvais. 1984. Acetolactate synthase is the site of action of two sulfonylurea herbicides in higher plants. Science, 224:1443-1445. 
Chaleff, R.S. and T.B. Ray. 1984. Herbicide-resistant mutants from tobacco cell cultures. Science, 223:1148-1151.

Comai, L. and D. Stalker. 1986. Mechanism of action of herbicides and their molecular manipulation. Oxford Surveys of Plant Mol. and Cell Biol. Oxford: Clarendon Press 3:167196.

Darlington, C.D. and L.F. La Cour. 1976. The handling of chromosomes, 6 th ed. George Allen and Unwin, London.

Devine, T.E., R.R. Seaney, D.L. Linscott, R.D. Hagin and N, Brace. 1975. Results of breeding for tolerance to 2,4-D in birdsfoot trefoil. Crop Sci. 15:721-724.

Donn, G., E. Tischer, J.A. Smith and H.M. Goodman. 1984. Herbicide resistant alfalfa cells: an example of gene amplification in plants. J. Mol. Appl. Genet. 2:621-635.

Duncan, D.R. and J.M, Widholm. 1986. Cell selection for crop improvement. Plant Breed. Rev. 4:153-173.

Du Pont 1984. Fechnical information bulletin on DPX-M6316 dated 2/1/84. Photocopy, $21 \mathrm{pp}$.

Du Pont Technical information bulletin on Classic experimental herbicide (formerly DPX-F6025) no date. Photocopy, 7 pp.

Dyer, W.E., S.C. Weller, R.A. Bressan and K.M. Herrmann. 1988 . Glyphosate tolerance in tobacco (Nicotiana tabacum L,) Plant Physiol. 88:661-666.

Eberlein, C.V., K.M. Rosow, J.L. Geadelmann and S.J. Openshaw. 1989. Differential tolerance of corn genotypes to DPXM6316. Weed Sci. 37:651-657.

Ellis, B.E. 1978. Non-differential sensitivity to the herbicide metribuzin in tomato cell suspension cultures. Can. $J$. Plant Sci. 58:775-778.

Evans, D.A. and W.R. Sharp. 1988. Somaclonal variation and its application in plant breeding. IAPTC Newsletter. 54:2-10.

Falco, S.C. and K.S. Dumas. 1985. Genetic analysis of mutants of Salcharomyces cerevisiae resistant to the herbicide sulfometuron methyl. Genetics 109:21-35.

Gabard, J.M., P.J. Charest, V.N. Iyer and B.L. Miki. 1989. Cross-resistance to short residual sulfonylurea herbicides in transgenic tobacco plants. Plant Physiol. 91:574-580. 
Gamborg, O.L., R.A. Miller and K. Ojima. 1968. Nutrient requirements of suspension cultures of soybean root cells. Exp. Cell Res. 50:151-158.

Grant, W.F. and G.C. Marten. 1985. Birdsfoot treforl. In Forages: science of grassland agriculture, 4 th ed. M.E. Heath, D.S. Metcalfe and R.F. Barnes, eds. Iowa State Unıv. Press, Ames, Iowa. pp. 98-108.

Grant, W.F., M.R. Bullen and D. de Nettancourt. 1962. The cytogeretics of Lotus. I. Embryo-cultured interspecif $1 \mathrm{C}$ diploid hybrids closely related to $L$. corniculatus. Can. J. Genet. Cytol. 4:105-128.

Green, C.E. 1978. In vitro plant regeneration in cereals and grasses. In Frontiers of plant tissue culture; Proc. 4th Int, Congr. Plant Tiss. Cell Cult. T.A. Thorpe, ed. IAPTC. Calgary pp. 411-418.

Green, C.E. and R.L. Phillips, 1975, Plant regeneration from tissue cultures of maize. Crop Sci. 15:417-421.

Gressel J., S. 211kah and G. Ezra. 1978. Herbicide action, resistance and screening in cultures vs, plants. In Frontiers of plant tissue culture. Proc. 4th Int. Congr. Plant Tissue Cell Cult. T.A. Thorpe ed. IAPTC. Calgary. pp $427-436$.

Haughn, G.W. and C.R. Somerville. 1986. Sulfonylurea-resistant mutants of Arabidopsis thaliana. Mol. Gen. Genet. 204:430434 .

Hoveland, C.S., R.L. Haaland, R.R. Harris and J.A. MCGurre. 1982. Birdsfoot trefoil in Alabama. Ala. Agric. Exp. Sta. Bull. No. 537 .

Hughes, K. 1983. Selection for herbicide resistance. In Handbook of plant cell culture, Techniques for propagation and breeding. Evans et al, ed. Macmillan, N.Y. 1:442-459.

Jordan, M.C. and A. McHughen. 1987. Selection for chlorsulfuron resistance in flax (Linum usitatissimum) cell cultures. J. Plant Physiol. 131:333-338.

Karp, A., and S.W.J. Bright. 1985. On the causes and orıgins of somaclonal variation. In Oxford Surveys of Plant Molecular and Cell Biology, B.J. Miflin, ed. Oxford: Clarendon Press. $2: 199-234$. 
Knowlton, S., B.J. Mazur and C.J. Arntzen. 1988. Creation and field testing of sulfonylurea-resistant crops. In Genetic improvements of agriculturally important crops: progress and issues. R.T. Fraley, N.M. Frey and J. Schell. Cold Spring Harbor, NY. pp. 55-60

Larkin, P.J. 1987. Somaclonal variation: history, method and meaning. Iowa state Journal of Research 61:393-434.

Larkin, P.J. and W.R. Scowcroft. 1981. Somaclonal variation - a novel source of variability from cell cultures for plant improvement. Theor. Appl. Genet. 60:197-214.

Larkin, P.J. and W.. Scowcroft. 1983. Somaclonal variation and eyespot toxin colerance in sugarcane. Plant cell Tissue Organ Culture 2:111-121.

LaRossa, R.A. and J.V. Schloss. 1984. The sulfonylurea herbicide sulfometuron methyl is an extremely potent and selective inhibitor of acetolactate synthase in Salmonella typhimurium. J. Biol. Chem. 259:8753-8757.

Lee, M. and R.L. Phillips. 1988. The chromosomal basis of somaclonal variation. Ann. Rev. Plant Physiol. Plant Mol. Biol. 39:413-437.

Levitt, G. 1983. Sulfonylureas, new herbicides. In Pesticide Chemistry, Human Welfare and the Environment. J. Miyamoto, and P.C. Kearney. eds. $1: 243-250$,

Machado, V.S., A. Ali and J. Shupe. 1983. Herbıcide-resistant rutabagas: a new approach to weed control. Highlights Agric. Res. Ont. 6(4):8-10.

Machean N. and W.F. Grant. 1987. Evaluation of birdsfoot trefoil (Lotus corniculatus L.) regenerated plants following in vitro selection for herbicide tolerance. Can. J. Bot. $65: 1275-1280$.

Madil1, J.E., W.E. Curnoe and D.W. MacDonald. 1980. Successful forage establishment. Agdex Publications No. $120 / 22$.

Mazur, B.J. and S.C. Falco. 1989. The development of herbicide resistant crops. Annu. Rev. Plant Physiol. Plant Mol Biol. $40: 441-470$.

McClintock, B. 1983. Trauma as a means of initiating change in genome organization and expression. In Vitro 19:283-284. 
McCoy, T.J., R.L. Phillips and H.W. Rines. 1982. CytogenetlC analysis of plants regenerated from oat (Avena sativa) tissue cultures; high frequency of partial chromosome loss. Can. J. Genet. Cytol. 24:37-50.

Meredith, C.P. 1984. Selecting better crops from cultured cells. In Gene manipulation in plant improvement. J.P. Gustafson, ed. Plenum, N.Y. pp. 503-528.

Meredith, C.P, and P.S. Carlson. 1982. Herbicide resistance in plant cell cultures. In Hexbicide resistance in plants. H.M. LeBaron and J. Gressel, eds. John Wiley, N.Y. pp. 275 291.

Mitra, G.C. 1985. Somaclonal variation as a strategy for plant improvement. Cell Chromosome Res. 8:59-68.

Mitra, J. and F.C. Steward. 1961. Growth Induction in cultures of Haplopappus gracilis. Il. The behaviour of the nucleus. Am, J, Bot. $48: 358-368$

Murashige, T. and F. Sknog. 1962. A revised medium for rapid growth and bioassays with tobacco tissue cultures. Physiol. Plant. 15:473-497.

Murashige, $T$ and $R$. Nakano. 1967. Chromosome complement as a determinant of the morphogenic potential of tobacco cells. Am. J. Bot. 54:963-970.

Orton, T.J. 1984. Genetic variation in somatic tissues: Method or madness? Adv. Plant Pathol. 2:153-189.

Peschke, V.M., R.L. Phillips and B.G. Genegebach. 1987. Transposable elements activity in progeny of regenerated maize plants. In vitro Cell. Devel. Biol. 23:A59.

Petit, A., J. Stougaard, A. Kuhle, K. A. Marcker and J. Tempe. 1987. Transformation and regeneration of the legume Lotus corniculatus: A system for molecular studies of symbiotic nitrogen fixation. Mol. Gen. Genet. 207:245-250.

Raelson, J.V. and W.F. Grant. 1989. An 1soenzyme study in the genus Lotus (Fabaceae). Experimental protocols and genetic basis of electrophoretic phenotype. Theor. Appl. Genet. $77: 595-607$.

Ray, T.B. 1980. Studies on the mode of action of DPX-4189. Proc. Brit. Crop prot. Conf. Weeds. 1:7-14. 
Ray, T.B. 1982. The modf: of action of chlorsulfuron: new herbicide for cereals. Pest. Biochem. Physicil. 17:10-17.

Ray, T.B. 1984. Site of action of chlorsulfuron, Plant Physiol. 75:827-831.

Ray T.B. 1985. The sjte of action of the sulfonylurea herbicides. Proc. British Crop Prot. Conf, weeds 1:131-17.

Saari, L.L., J.C. Cotterman, and M.M. Primianı. 1990. Mechanism of sulfonylurea herbicide resistance in the broadleaf weed, Kochia scoparia. Plant Physiol. 93:55-61.

Sacristan, M.D. 1971. Karyotypic changes in callus cultures from haploid and diploid plants of Crepis capillaris L. Wallr. Chromosoma 33:273-283.

Saxena, P.K. and J. King. 1988. Herbicide resistance in Datura innoxia. Cross-resistance of sulfonylurea-resistant cell lines tc imidazolinones. Plant Physiol. 86:863-867.

Scheel, D. and J.E. Casıda. 1985. Sulfonylurea herbicides: Growth inhibition in soybean cell suspension cultures and in bacteria correlated with block in biosynthesis of valine, leucine or isoleucine. Pest Biochem. Physiol. $23: 398-412$.

Schimke, R.T., S.W. Sherwood, A.B. Hill and R.N. Johnston. 1986 . Overreplication and recombination of DNA in higher eukaryotes: potential consequences and biological implications. Proc. Natl. Acad. Sci. USA. 83-2157-2161

Sebastian S.A. and R.S. Chaleff. 1987. Soybean mutants with increased tolerance for sulfonylurea herbicides. Crop Sci. $27: 948-952$.

Sebastian S.A., G.M. Fader, J.F. Ulrich, D.R. Forney, and R.S. Chaleff. 1989. Semidominant soybean mutation for resistance to sulfonylurea herbicides. Crop Sci. 29:1403-1408.

Shepard, J.F. 1981. Protoplasts as sources of disease resistance in plants. Annu. Rev. Phytopath. 19:145-166.

Singer, S.R., and C.N. McDaniel. 1985. Selection of glyphosate tolerant tobacco calli and the expression of this tolerance in regenerated plants. Plant Physiol. 78:411-416.

Sionis, S.D., H.G. Drobny, P. Lefebvre, and M.E. Upstone. 1985. DPX-6316, a new sulfonylurea cereal herbicide. British Crop Prot. Conf., Weeds. 1:49-54. 
Stark G.R. and G.M. Wahl. 1984. Gene amplificatıon. Annu. Rev. Biochem. 53:447-491.

Sunderland, N. 1973. Nuclear cytology. In Plant tissue and cell culture. H.E. Street, ed. Blackwell: Oxford Univ. Press. pp. 205-239.

Swanson, E.B, and D.T. Tomes. 1980a. Plant regeneration from cell cultures of Lotus corniculatus L. and the selection and characterization of 2,4-D tolerant cell lines. Can. J. Bot. 58:1205-1209.

Swanson, E.B, and D.T. Tomes. 1980b. In vitro responses of tolerant and susceptible lines of Lotus corniculatus L. Lo 2,4-D. Crop Sci. 20:792-795.

Swanson, E.B., M.P. Coumans, G.L. Brown, J.D. Patel and W.D. Beversdorf. 1988. The characterization of herbicide tolerant plants in Brassica napus L. after in vitro selection of microspores and protoplasts. Plant cell Rep. $7: 83-87$.

Sweetser, P.B., G.S. Schow and J.M. Hutchison. 1982. Metabolism of chlorsufuron by plants: Biological basis for selectivity of a new herbicide for cereals. Pestic. Biochem. Physiol. $17: 18-23$.

Tomes, D.T. 1982. Selection at the cellular level in crop plants: potential for agriculture. Highlights Agr 1C. Res. Ont. $5(1): 1-3$.

Torrey, J.G. 1967. Morphogenisis $2 n$ relation to chromosomal constitution in long-term plant tissue culture. Physiol. Plant. 20:265-275

Wakefield, R.C. and N. Skaland. 1965. Effects of seeding rate and chemical weed control on establishment and subsequent growth of alfalfa (Medicago sativa L.) and birdsfoot. trefoil (Lotus corniculatus L.) Agron. J. 57:547-550.

Webb, K.J. 1986. Transformation of forage legumes using Agrobacterium tumfaciens. Theor. Appl. Genet. 72:53-58.

Widholm, J.M. 1977. Isolation of biochemical mutants in cultured cells. In Mol. gen. modification of eucaryotes. I. Rubinstein, ed. Academic Press N.Y. pp. 57-65

Xiao, W., P.K. Saxena, J. King and G.H. Rank. 1987. A transient. duplication of the acetolactate synthase gene in a cell culture of Datura innoxia. Theor. Appl. Genet. 74:417-422. 
Appendix 1

Media Composition

Chemical

$\mathrm{Na}_{4} \mathrm{NO}_{3}$
$\mathrm{NaH}_{2} \mathrm{PO}_{4} \cdot \mathrm{H}_{2} \mathrm{O}$
$\mathrm{KNO}_{3}$
$\left(\mathrm{NH}_{4}\right)_{2} \mathrm{SO}_{4}$
$\mathrm{MgSO}_{4} \cdot 7 \mathrm{H}_{2} \mathrm{O}$
$\mathrm{CaCl}_{2} \cdot 2 \mathrm{H}_{2} \mathrm{O}$
$\mathrm{KH}_{2} \mathrm{PO}_{4}$

Micronutrients

$\mathrm{MnSO}_{4} \cdot \mathrm{H}_{2} \mathrm{O}$

$\mathrm{MnSO}_{4} \cdot 4 \mathrm{H}_{2} \mathrm{O}$

$\mathrm{H}_{3} \mathrm{BO}_{3}$

$\mathrm{ZnSO} \cdot 7 \mathrm{H}_{2} \mathrm{O}$

$\mathrm{KI}$

$\mathrm{Na}_{2} \mathrm{MOO}_{4}, 2 \mathrm{H}_{2} \mathrm{O}$

$\mathrm{CuSO}_{4} \cdot 5 \mathrm{H}_{2} \mathrm{O}$

$\mathrm{CoCl}_{2} \cdot 6 \mathrm{H}_{2} \mathrm{O}$
$-$

150.0

2500.0

134.0

250.0

150.0
MS

$\mathrm{mg} / \mathrm{L}$
1650.0

$-$

1900.0

$-$

370.0

440.0

170.0

FENAEDTA

10.0

$-$

3.0

2.0

0.75

0.25

0.025

0.025
$-$

22.30

6.20

8.60

0.83

0.25

0.025

0.025

Vitamins and Growth Regulators*

Nicotinic acid Thiamine. HCL Pyridoxine. HCL myo - Inositol

40.0

40.0

Sucrose

1.0

10.0

1.0

100.0

0.5

0.1

0.5

100.0

$20.0 \mathrm{~g}$

$30.0 \mathrm{~g}$

T.C. agar

$8.0 \mathrm{~g}$

$8.0 \mathrm{~g}$

$\mathrm{pH}$

5.5

5.7

*Appropriate growth regulators were added as needed:

$5.0 \mathrm{mg} / \mathrm{L} \mathrm{2,4-D} \mathrm{-} \mathrm{Callus} \mathrm{induction} \mathrm{medium}$

$0.5 \mathrm{mg} / \mathrm{L} \mathrm{BA}$ - Shoot induction medium

$0.2 \mathrm{mg} / \mathrm{L} \mathrm{NAA}$ - Root induction medium 
Appendix 2

Leo callus culture: pretests to determine dose/response range for Classic and Harmony

\begin{tabular}{lllll}
\hline \hline $\begin{array}{l}\text { Herbicide } \\
\text { M concentration }\end{array}$ & \multicolumn{2}{c}{ Classic } & Harmony & \\
\hline & $F W^{*}$ & $\begin{array}{c}\text { Percent } \\
\text { of Control }\end{array}$ & FW & $\begin{array}{l}\text { Percent } \\
\text { of Control }\end{array}$ \\
\hline 0.0 & 1.392 & 100.0 & 1.301 & 100.0 \\
$1 \times 10^{-8}$ & 1.333 & 95.76 & 1.251 & 96.2 \\
$1 \times 10^{-7}$ & 1.110 & 79.74 & 0.911 & 70.0 \\
$1 \times 10^{-6}$ & 0.846 & 60.77 & 0.662 & $50.9^{* *}$ \\
$1 \times 10^{-5}$ & 0.645 & $46.34^{* *}$ & 0.528 & 40.6 \\
$1 \times 10^{-4}$ & 0.477 & 34.27 & 0.498 & 38.3 \\
\hline \hline
\end{tabular}

* Fresh weight is the mean of three replicate measurements after two weeks growth on solidified selection media. Starting weight of callus was $0.5 \mathrm{~g} /$ petri plate.

** Approximate $I_{50}$ value 
Append $1 \times 3$

In vitro germination of outcrossed seeds of etght fertile cell irnes on Harmony selection medium $\left(10^{-5} \mathrm{M}\right)$

\begin{tabular}{|c|c|c|c|c|c|c|c|c|c|c|c|c|c|}
\hline \multicolumn{2}{|c|}{ Cell Line } & \multicolumn{3}{|c|}{ N Tested } & \multicolumn{5}{|c|}{ N Resistant* } & \multicolumn{4}{|c|}{$z$ Resistant } \\
\hline & & Exp & 1 Exp & 2 Exp3 & Total & Expl & Exp2 & Exp3 & Total & Exp1 & Exp2 & Exp3 & Total \\
\hline \multirow[t]{3}{*}{ (A) } & Leo & 91 & 59 & 14 & 164 & 2 & 1 & 0 & 3 & 2.2 & 1.7 & 0.0 & 1.8 \\
\hline & $3-6$ & 81 & 97 & - & 78 & 0 & 1 & - & 1 & 1.0 & 1.0 & - & 0.6 \\
\hline & $5-12$ & 61 & 57 & - & 118 & 0 & 1 & - & 1 & 0.0 & 1.8 & - & 0.9 \\
\hline (B) & $5-14$ & 52 & 2 & - & 54 & 1 & 0 & - & 1 & 1.9 & 0.0 & - & 1.9 \\
\hline \multirow[t]{4}{*}{ (C) } & $1-1$ & 31 & 61 & 45 & 137 & 14 & 23 & 19 & 56 & 45.2 & 37.7 & 42.2 & 40.9 \\
\hline & $4-10$ & 45 & 115 & - & 160 & 0 & 3 & - & 3 & 0.0 & 2.6 & - & 1.9 \\
\hline & $5-1$ & 37 & 28 & 36 & 101 & 3 & 10 & 13 & 36 & 35.1 & 35.7 & 36.1 & 35.6 \\
\hline & $5-10$ & 30 & 13 & 31 & 74 & 10 & 4 & 12 & 26 & 33.3 & 30.8 & 38.7 & 35.1 \\
\hline
\end{tabular}

-Seeds that germinated and grew secondary leaves on selection med a with $10^{-5}$ M Harmony from 3 separate experiments.

(A, =control from : ed

$\left(D^{\prime} ;=\right.$ control from tissue culture

(C) =selected mutants from tissue culture 
Appendix 4

Analysis of the effect of herbicide treatment on callus growth of regenerants.

Dependant variable: Callus growth after 2 weeks

\begin{tabular}{lccccc}
\hline \hline Source & DF & Anova SS & Mean Square & F value & Pr,$F$ \\
Genotype & 5 & 0.32642483 & 0.06528497 & $4.92 \star \star$ & 0.0111 \\
Herbicide level & 1 & 0.19801667 & 0.19801667 & $14.93 \star \star$ & 0.0023 \\
G*H (interaction) & 5 & 0.14729583 & 0.02945917 & 2.22 & 0.1195
\end{tabular}

Dependant variable: Callus growth after 4 weeks

\begin{tabular}{lccccc}
\hline Source & DF & Anova SS & Mean Square & F Value & Pr $>F$ \\
\hline Genotype & 5 & 2.04146200 & 0.40829240 & $14.70 \star \star$ & 0.001 \\
Herbicide & 1 & 2.89398150 & 2.89398150 & $104.16 \star \star$ & 0.0001 \\
G*H (interaction) & 5 & 1.69963100 & 0.33992620 & $12.24 \star \star$ & 0.0002
\end{tabular}

\begin{tabular}{|c|c|c|c|c|c|c|}
\hline Contrast & Cell line & $\mathrm{DF}$ & Contrast SS & Mean Square & F value & $\operatorname{Pr}>\mathrm{F}$ \\
\hline$h(G 1)$ & (Leo) & 1 & 0.94575625 & 0.94575625 & $34.04 \star \star$ & 0.0001 \\
\hline$h(G 2)$ & $(5-14)$ & 1 & 3.10640625 & 3.10640625 & $111.81 \star \star$ & 0.0001 \\
\hline$h(G 3)$ & $(1-1)$ & 1 & 0.19980900 & 0.19980900 & $7.19 \star$ & 0.0200 \\
\hline$h(G 4)$ & $(5-1)$ & 1 & 0.06051600 & 0.06051600 & $2.18 \mathrm{~ns}$ & 0.1657 \\
\hline$h(G 5)$ & $(5-7)$ & 1 & 0.09363600 & 0.09363600 & $3.37 \mathrm{~ns}$ & 0.0913 \\
\hline$h(G 6)$ & $(5-10)$ & 1 & 0.18748900 & 0.18748900 & $6.75^{\star}$ & 0.0233 \\
\hline
\end{tabular}

$\star, \star \star$, significant at the 0.05 and 0.01 level respectively ns, not significant at the 0.05 level

contrasts compare the control ( 0 herbicide) vs. herbicide treatment of individual genotype levels. 
Appendix 5

Analysis of the effect of herbicide treatments on height of cell Iines (genotypes) at week $0 /$ week $6 /$ and increase in height over this period from: Indoor study

Dependent Variable: HEIGHT AT WEEK 0

\begin{tabular}{llcccc}
\hline Source & DF & Anova SS & Mean Square & F value Pr $>F$ \\
Genotype & i3 & 43.57738095 & 3.35210623 & 1.21 ns & 0.3208 \\
\hline
\end{tabular}

Dependent Variable: HEIGHT AT WEEK 6

\begin{tabular}{lccccc}
\hline Source & DF & Anova SS & Mean Square & F value Pr $>$ F \\
Genotype & 13 & 2231.142857 & 171.626374 & $26.77 \star \star$ & 0.0001 \\
\hline
\end{tabular}

Dependent Variable: INCREASE IN HEIGHT (WK6-WKO)

\begin{tabular}{lcccccc}
\hline Source & DF & Anova SS & Mean Square & F Value & Pr $>F$ \\
Genotype & 13 & 1862.625000 & 143.278846 & $18.85 \star \star$ & 0.0001 \\
\hline
\end{tabular}

$\star *$, significant at the 0.01 level

ns, not significant st the 0.05 level 
Appendix 6A

Analysis of effects of three herbicide treatments and 12 cell lines (genotypes) on yield - from field study 1989

Dependent Variable: DRY WEIGHT YIELD

\begin{tabular}{lrrrrr}
\hline \hline Source & DF & Type III SS & Mean Square & F Value & Pr $>F$ \\
\hline R & 2 & 1834.2497 & 917.1249 & 0.82 & 0.4429 \\
G & 11 & 247322.9583 & 22483.9053 & $20.22 \star \star$ & 0.0001 \\
G*H & 2 & 127319.6986 & 63659.8493 & $57.26 \star \star$ & 0.0001 \\
\hline
\end{tabular}

Contrasts of herbicide levels within genotypes

\begin{tabular}{|c|c|c|c|c|c|c|c|c|c|}
\hline \multicolumn{2}{|c|}{ Contrast } & $\frac{\text { Cell }}{1-1}$ & $\begin{array}{l}\text { line } \\
\text { (C) }\end{array}$ & DF & Contrast SS & Mean Square & \multicolumn{2}{|l|}{ F Value } & $\operatorname{Pr}>F$ \\
\hline $\begin{array}{l}\mathrm{H} \\
\mathrm{H} \\
\mathrm{H} \\
\mathrm{H} \\
\mathrm{H} \\
\mathrm{H} \\
\mathrm{H} \\
\mathrm{H} \\
\mathrm{H} \\
\mathrm{H} \\
\mathrm{H} \\
\mathrm{H}\end{array}$ & $\begin{array}{l}\text { IN G1 } \\
\text { IN G2 } \\
\text { IN G3 } \\
\text { IN G4 } \\
\text { IN G5 } \\
\text { IN G6 } \\
\text { IN G7 } \\
\text { IN G8 } \\
\text { IN G9 } \\
\text { IN } G 10 \\
\text { IN Gi1 } \\
\text { IN } \\
\text { G12 }\end{array}$ & $\begin{array}{r}1-1 \\
1-10 \\
2-14 \\
4-10 \\
4-12 \\
4-16 \\
4-17 \\
5-1 \\
5-10 \\
5-12 \\
5-14 \\
\text { Leo }\end{array}$ & $\begin{array}{l}\text { (C) } \\
\text { (C) } \\
\text { (C) } \\
\text { (C) } \\
\text { (C) } \\
(\text { C) } \\
\text { (C) } \\
(\text { C) } \\
\text { (A) } \\
\text { (B) } \\
\text { (A) }\end{array}$ & $\begin{array}{l}2 \\
2 \\
2 \\
2 \\
2 \\
2 \\
2 \\
2 \\
2 \\
2 \\
2 \\
2\end{array}$ & $\begin{array}{r}11488.66667 \\
1460.72079 \\
9177.18630 \\
92317.09244 \\
2124.66667 \\
202.66667 \\
129.96446 \\
3859.45210 \\
1571.87088 \\
59540.66667 \\
9814.22222 \\
52714.88889\end{array}$ & $\begin{array}{r}5744.33333 \\
730.36039 \\
4588.59315 \\
46158.54622 \\
1062.33333 \\
101.33333 \\
64.98223 \\
1929.72605 \\
785.93544 \\
29770.33333 \\
4907.11111 \\
26357.44444\end{array}$ & $\begin{array}{r}5.17 \\
0.66 \\
4.13 \\
41.52 \\
0.96 \\
0.09 \\
0.06 \\
1.74 \\
0.71 \\
26.78 \\
4.41 \\
23.71\end{array}$ & $\begin{array}{l}\star \star \\
\text { ns } \\
\star \\
\star \star \\
\text { ns } \\
\text { ns } \\
\text { ns } \\
\text { ns } \\
\text { ns } \\
\star \star \\
\star \\
\star \star\end{array}$ & $\begin{array}{l}0.0084 \\
0.5219 \\
0.0207 \\
0.0001 \\
0.3901 \\
0.9130 \\
0.9433 \\
0.1846 \\
0.4970 \\
0.0001 \\
0.0161 \\
0.0001\end{array}$ \\
\hline
\end{tabular}

contrasts compare the control vs. herbicide treatment at individual genotype levels.

$\star$, $\star$, significant at the $0.05,0.01$ level respectively ns, not significant at the 0.05 level. 
Appendix 6B

Analysis of the effect of herbicide treatment on days to flowering (1989)

Dependent Variable: DAYS TO FLOWER MATURITY

\begin{tabular}{lrrrrr}
\hline \hline Source & DF & Type III SS & Mean Square & F value & Pr $>F$ \\
\hline R & 2 & 7.436163 & 3.718081 & 0.46 ns & 0.6342 \\
G & 11 & 670.587487 & 60.962499 & 7.52 & 0.0001 \\
H & 2 & 1837.476407 & 918.738203 & $113.32 \star \star$ & 0.0001 \\
$G^{\star} H$ & 22 & 1279.365730 & 58.152988 & $7.17 \star \star$ & 0.0001 \\
\hline
\end{tabular}

Appendix 6C

Analysis of the effect of herbicide treatment on days to pod maturity (1989)

Dependent Variable: DAYS TO POD MATURITY

\begin{tabular}{lrrrrr}
\hline \hline Source & DF & Type III SS & Mean Square & F value & Pr $>F$ \\
\hline$R$ & 2 & 0.101794 & 0.050897 & 0.01 ns & 0.9924 \\
$G$ & 11 & 550.626791 & 50.056981 & $7.47 \star \star$ & 0.0001 \\
$H$ & 2 & 2015.370244 & 1007.685122 & $150.31 \star \star$ & 0.0001 \\
$G{ }^{H}$ & 22 & 1183.932211 & 53.815101 & $8.03 \star \star$ & 0.0001 \\
\hline
\end{tabular}

$\star, \star \star$, significant at the 0.05 and 0.01 level respectively.

$n s$, not significant at the 0.05 level.

$\mathbf{R}=$ replications

$\mathbf{G}=$ genotypes

$H=$ herbicide treatments 
Appendix 7

Analysis of ALS inhibition, as a percent of respective controls, of four cell lines at four herbicide levels

\begin{tabular}{lrrrrr}
\hline Source & DF & Type III SS & Mean Square & F value & Pr,$F$ \\
\hline Genotype & 3 & 1533.26060 & 511.08687 & $5.60 \star \star$ & 0.0025 \\
Herbicide & 3 & 31716.33390 & 10572.11130 & $115.79 \star \star$ & 0.0001 \\
G*H (interaction) & 9 & 120.24337 & 13.36037 & $0.15 \mathrm{~ns}$ & 0.9978
\end{tabular}

$\star \star$, significant at the 0.01 level.

ns, not significant at the 0.05 level.

\begin{tabular}{llll}
\hline T Grouping & Mean & G & Cel1 line \\
\hline A* & 34.835 & 4 & $5-10$ \\
A & 29.161 & 2 & $1-1$ \\
A & 27.984 & 3 & $5-1$ \\
B & 20.446 & 1 & Leo
\end{tabular}

* Means with the same letter are not significantly different at the 0.05 level 